\title{
Resistance to Botrytis cinerea in Solanum lycopersicoides involves widespread transcriptional reprogramming
}

\author{
Jonathon E Smith', Bemnet Mengesha², Hua Tang ${ }^{2}$, Tesfaye Mengiste ${ }^{2}$ and Burton H Bluhm*
}

\begin{abstract}
Background: Tomato (Solanum lycopersicum), one of the world's most important vegetable crops, is highly susceptible to necrotrophic fungal pathogens such as Botrytis cinerea and Alternaria solani. Improving resistance through conventional breeding has been hampered by a shortage of resistant germplasm and difficulties in introgressing resistance into elite germplasm without linkage drag. The goal of this study was to explore natural variation among wild Solanum species to identify new sources of resistance to necrotrophic fungi and dissect mechanisms underlying resistance against $B$. cinerea.
\end{abstract}

Results: Among eight wild species evaluated for resistance against $B$. cinerea and A. solani, S. lycopersicoides expressed the highest levels of resistance against both pathogens. Resistance against $B$. cinerea manifested as containment of pathogen growth. Through next-generation RNA sequencing and de novo assembly of the S. Iycopersicoides transcriptome, changes in gene expression were analyzed during pathogen infection. In response to $B$. cinerea, differentially expressed transcripts grouped into four categories: genes whose expression rapidly increased then rapidly decreased, genes whose expression rapidly increased and plateaued, genes whose expression continually increased, and genes with decreased expression. Homology-based searches also identified a limited number of highly expressed B. cinerea genes. Almost immediately after infection by B. cinerea, S. Iycopersicoides suppressed photosynthesis and metabolic processes involved in growth, energy generation, and response to stimuli, and simultaneously induced various defense-related genes, including pathogenesis-related protein 1 (PR1), a beta-1, 3-glucanase (glucanase), and a subtilisin-like protease, indicating a shift in priority towards defense. Moreover, cluster analysis revealed novel, uncharacterized genes that may play roles in defense against necrotrophic fungal pathogens in S. Iycopersicoides. The expression of orthologous defense-related genes in S. Iycopersicum after infection with $B$. cinerea revealed differences in the onset and intensity of induction, thus illuminating a potential mechanism explaining the increased susceptibility. Additionally, metabolic pathway analyses identified putative defense-related categories of secondary metabolites.

Conclusions: In sum, this study provided insight into resistance against necrotrophic fungal pathogens in the Solanaceae, as well as novel sequence resources for $S$. Iycopersicoides.

Keywords: Necrotrophic pathogenesis, Botrydial, Phytoalexins

\footnotetext{
* Correspondence: bbluhm@uark.edu

'Department of Plant Pathology, University of Arkansas Division of Agriculture, 217 Plant Sciences, Fayetteville, AR 72701, USA

Full list of author information is available at the end of the article
} 


\section{Background}

Plant pathogens are classified as necrotrophs, biotrophs, or hemibiotrophs based on their modes of nutrition [1-3]. Biotrophs feed on living tissue and subtly manipulate host physiology to obtain nutrients [1,2]. Necrotrophs kill host cells to obtain nutrients, often inducing expanding, necrotic lesions $[1,4]$. Hemibiotrophs undergo a biotrophic stage of nutrition before shifting to a necrotrophic strategy for nutrient uptake $[1,3]$. Due to their fundamentally distinct mechanism of pathogenesis, biotrophs have evolved mechanisms to suppress cell death while necrotrophs promote it as a virulence strategy [5-8]. When hosts fail to constrain necrosis caused by necrotrophs and hemibiotrophs, diseases can culminate in the death and decay of the entire plant. Toxins and hydrolytic enzymes are central to virulence in necrotrophs but have minimal contributions to biotrophic pathogenesis $[2,4,8]$. Consequently, host responses to pathogen infection vary depending on the nature of the pathogen. Whereas the molecular basis of resistance against biotrophic infection strategies is becoming increasingly well understood $[9,10]$, the current understanding of plant resistance against necrotrophic fungi is fragmentary.

Necrotrophs are classified as either broad host-range or host-specific pathogens [8]. While broad-host-range necrotrophs produce a variety of cell wall-degrading enzymes, phytotoxic metabolites, and cell death elicitors that kill host cells and induce necrosis, the ability of host-specific necrotrophs to cause disease is generally attributed to the production of toxins that have activity on a limited number of related plant species $[11,12]$. The broad host-range necrotroph, Botrytis cinerea, is a ubiquitous and cosmopolitan pathogen that causes gray mold disease on more than 200 host plants [13] with worldwide losses in affected crops estimated at $20 \%$ [14]. B. cinerea induces necrosis by producing toxins and reactive oxygen species $[15,16]$, and also manipulates hosts into producing oxidative bursts that facilitate colonization $[17,18]$. Two classes of toxins have been identified in B. cinerea that exhibit non-specific phytotoxicity: the sesquiterpene toxin, botrydial, and related metabolites, and the polyketide toxin, botcinic acid, and its derivatives [15,19-21]. In contrast to B. cinerea, Alternaria solani primarily infects members of the Solanaceae such as tomato, potato, peppers, and eggplant [22]. Like B. cinerea, A. solani uses toxins to induce necrosis in its hosts [23]. While as many as eleven toxins have been identified in cultures of $A$. solani, alternaric acid and solanopyrones $\mathrm{A}, \mathrm{B}$, and $\mathrm{C}$, have been implicated as the primary necrosis-inducing toxins $[22,24,25]$. Although necrosis of host tissues is known to be induced by toxins, additional, unknown factors may be involved in the host specificity of A. solani [24].

The Solanaceae is one of the world's most economically important plant families and includes vegetables, ornamentals, and medicinal plants [26]. Among the solanaceous crops, tomato (Solanum lycopersicum) is particularly susceptible to $B$. cinerea and $A$. solani $[27,28]$. Due to a lack of genetic resistance against necrotrophic fungal pathogens in commercial tomato cultivars, $B$. cinerea and $A$. solani inflict heavy losses, and thus frequent applications of fungicides are required for disease management. In the absence of chemical protection, over $50 \%$ of the annual tomato crop can be lost to necrotrophic pathogens [29]. Although tomato lacks resistance to B. cinerea and $A$. solani, robust resistance against some necrotrophic fungal pathogens has been identified in closely related species within the Solanaceae [30,31]. However, the underlying mechanisms of resistance have not been characterized at the molecular level, in part due to a lack of molecular resources for many members of the Solanaceae, particularly non-crop species.

Identification and characterization of genetic resistance against necrotrophic fungi would provide a crucial biological foundation for crop improvement within the Solanaceae. The overarching goal of this study was to identify and characterize resistance to necrotrophic fungal pathogens among members of the Solanaceae. To this end, we screened a panel of Solanum species for resistance to $B$. cinerea and $A$. solani and found that $S$. lycopersicoides (LA2951) showed a high level of resistance to both pathogens. This resistance manifested as constrained lesion expansion as well as reduced pathogen growth. Then, we generated gene expression profiles from S. lycopersicoides 24 and 48 hours after inoculation with $B$. cinerea, as well as a pre-infection baseline, via high-throughput RNA-sequencing (Roche-454). Analyses of the transcriptomes revealed that numerous genes were differentially expressed in $S$. lycopersicoides in response to $B$. cinerea, including pathogenesis-related proteins, proteases, a glucanase, and genes involved in biosynthesis of secondary metabolites. Additionally, a set of highly expressed $B$. cinerea genes was identified, which could facilitate the elucidation of fungal genes involved in necrotrophic pathogenesis.

\section{Results}

\section{Evaluation of resistance against necrotrophic fungi} among wild Solanum species

Resistance to $B$. cinerea has been previously reported in wild solanaceous plants $[30,32,33]$. However, to date, no study has quantitatively compared resistance to multiple necrotrophic fungal pathogens in Solanum species, and it is not known whether mechanisms of resistance to $B$. cinerea are the same for other necrotrophs. Therefore, three tomato varieties and eight wild Solanum species were evaluated for resistance against $B$. cinerea and $A$. solani (Figure 1). The tomato varieties VF-36 (S. lycopersicum, LA0490) and M-82 (S. lycopersicum, LA3475) are 

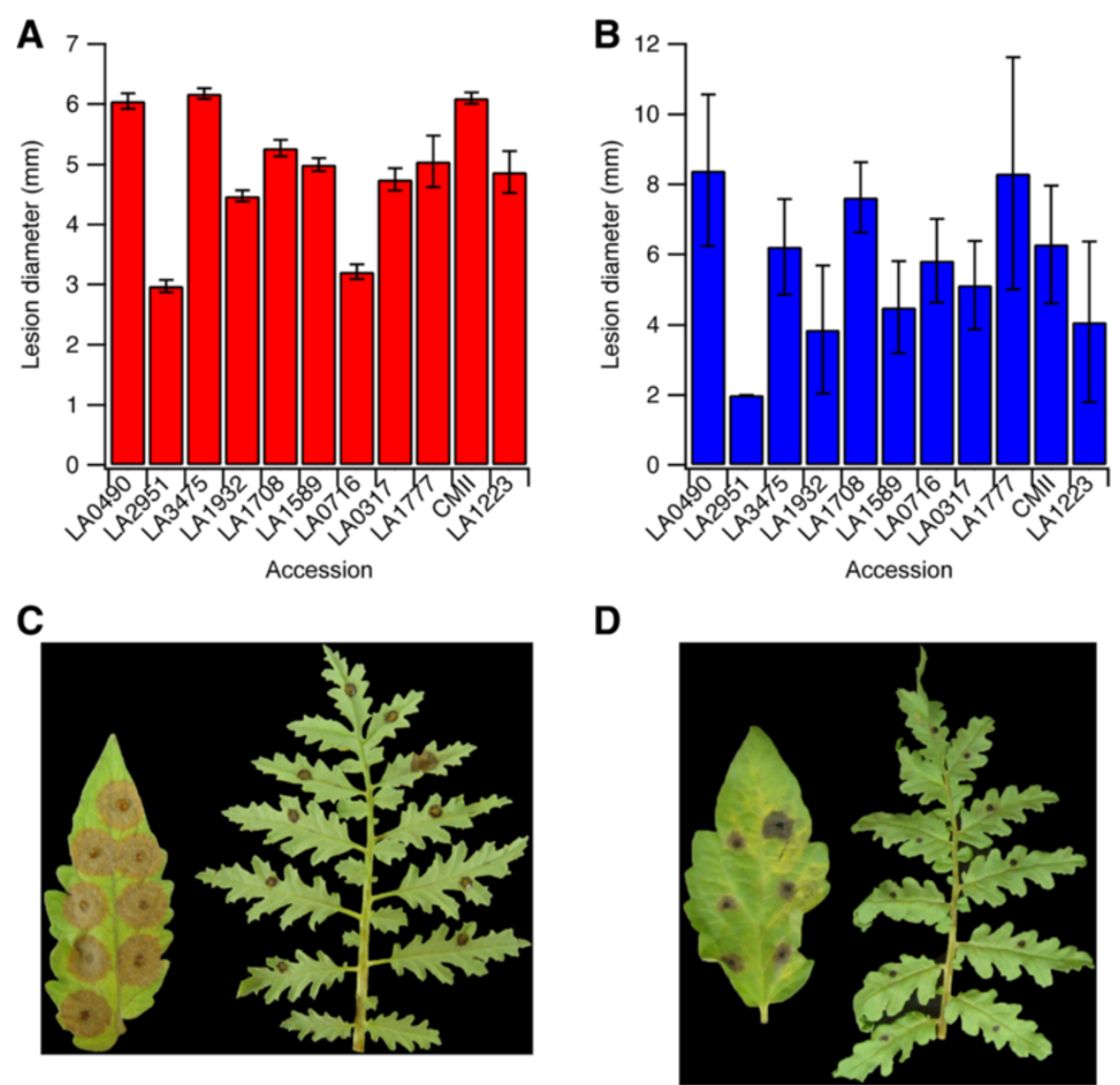

Figure 1 Comparison of resistance to necrotrophic fungal pathogens among Solanum species. Quantitative comparison of resistance to (A) B. cinerea and (B) A. solani among Solanum species. Visual comparison of disease development on S. lycopersicum and S. lycopersicoides 96 hours after inoculation with B. cinerea (C) and A. solani (D).

parents for introgression lines created from S. lycopersicoides and S. pennellii, respectively, and were selected as susceptible checks $[34,35]$. The variety Castlemart II was selected because of its common usage in tomato genetics studies. All of the wild Solanum species selected are native to South America; the center of origin for tomato is the Andean region of South America and thus wild species from this area are more likely to be naturally adapted to challenge by pathogens [36].

Of the eleven lines tested, Solanum lycopersicoides (LA2951) was the most resistant to both B. cinerea and A. solani (Figure 1A, B), suggesting the presence of broadspectrum resistance to necrotrophs. B. cinerea caused indistinguishably high levels of necrosis in all three $S$. lycopersicum varieties tested. In contrast, the wild Solanum species showed varying levels of resistance, which manifested as a reduction in lesion diameter compared to the S. lycopersicum varieties. The reduction in lesion diameter ranged from $13 \%$ for S. arcanum (LA1708) to $51 \%$ for S. lycopersicoides (LA2951). A high level of resistance to B. cinerea was also observed in S. pennellii (LA0716), which showed a $47 \%$ reduction in lesion diameter as compared to $S$. lycopersicum. Interestingly, resistance responses to $A$. solani followed a different pattern than observed for $B$. cinerea. Among the eleven lines tested, VF-36 (S. lycopersicum, LA0490) was the most susceptible. The $S$. lycopersicum varieties were not equally susceptible to A. solani; M- 82 and Castlemart II exhibited a $26 \%$ and $25 \%$ reduction in lesion diameter respectively as compared to VF-36. Among the wild species tested, S. lycopersicoides (LA2951) was the most resistant to A. solani, and appeared to exhibit even higher levels of resistance to $A$. solani than B. cinerea. In contrast, S. pennellii (LA0716) was only moderately resistant to $A$. solani but was highly resistant to $B$. cinerea. Therefore, given the high level of resistance of $S$. lycopersicoides to both necrotrophic pathogens, this accession was selected to investigate molecular mechanisms of resistance to necrotrophs (Figure 1C, D). B. cinerea was chosen to serve a model necrotroph in this study because it has a sequenced genome [37], readily sporulates in culture, and causes disease on all tomato varieties tested. 


\section{Characterization of resistance against B. cinerea in S. lycopersicoides}

To further define resistance against B. cinerea in S. lycopersicoides, the sequenced wild-type strain of $B$. cinerea (B05.10) was inoculated on S. lycopersicoides accession LA2951 (resistant to B. cinerea) and S. lycopersicum cv. Bradley (susceptible to $B$. cinerea). Symptoms of infection were observed by $48 \mathrm{~h}$ after inoculation in both S. lycopersicum and S. lycopersicoides (Figure 2A), although lesions were $61 \%$ larger on S. lycopersicum than S. lycopersicoides (Figure 2B). Symptoms initially appeared as small, water-soaked lesions that quickly became necrotic and spreading. By $72 \mathrm{~h}$ after inoculation, lesions on S. lycopersicum began to coalesce. Likewise, due to the leaf morphology of $S$. lycopersicoides, some lesions began to reach the edges of leaflets. However, lesions on S. lycopersicum were nearly twice the diameter of those on S. lycopersicoides (Figure 2B).

To determine whether the smaller lesions on S. lycopersicoides were due primarily to reduced pathogen growth, ergosterol was quantified from S. lycopersicum and S. lycopersicoides leaves inoculated with $B$. cinerea. Interestingly, fungal growth was not significantly different between $S$. lycopersicum and S. lycopersicoides $48 \mathrm{~h}$ after inoculation (Figure $2 \mathrm{C}$ ). However, by $72 \mathrm{~h}$ after inoculation, the ergosterol content of S. lycopersicum was over twice that of inoculated S. lycopersicoides leaves (Figure 2C). The increased detection of B. cinerea in S. lycopersicum as compared to $S$. lycopersicoides $72 \mathrm{~h}$ after inoculation correlated closely with observed levels of necrosis and indicates that suppression of fungal growth may be a primary component of resistance to $B$. cinerea in $S$. lycopersicoides.
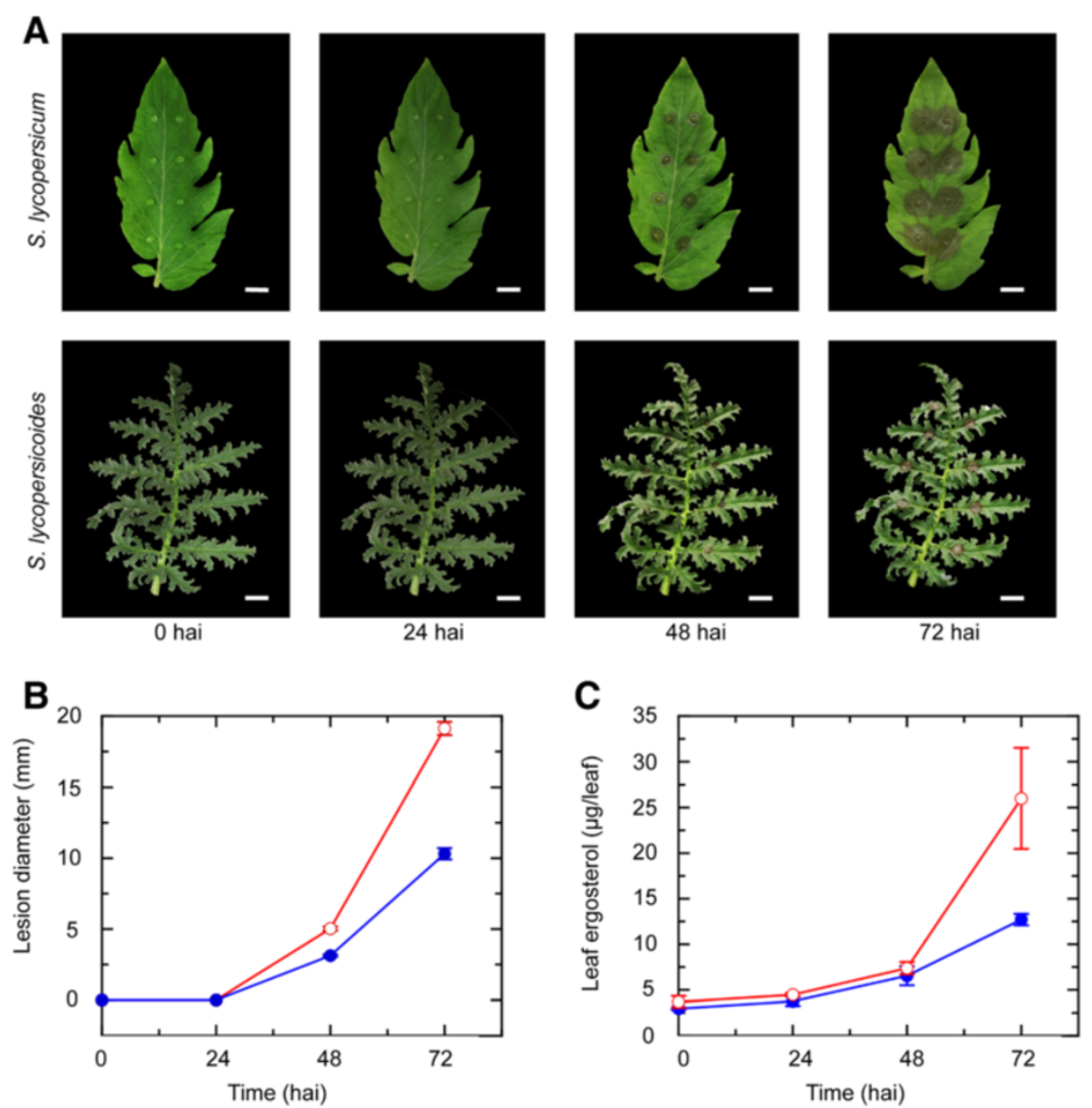

Figure 2 Comparison of disease development on Solanum lycopersicum and Solanum lycopersicoides. (A) Lesion development on S. Iycopersicum and S. Iycopersicoides was observed at 0, 24, 48, and 72 hours after inoculation (hai) with B. cinerea. White bars represent $10 \mathrm{~mm}$. (B) Lesion diameter and (C) ergosterol content were measured to quantify disease development and fungal growth, respectively, on $\mathbf{S}$. lycopersicoides (Blue) and S. lycopersicum (Red). (B) For lesion diameter, values represent the mean diameter of 32 individual lesions, and error bars indicate standard error. (C) For ergosterol content, values represent the mean of 3 separate leaves, and error bars indicate standard error. Both fungal growth and lesion diameter increased in S. Iycopersicum compared to S. Iycopersicoides at $72 \mathrm{~h}$ after inoculation. 
De novo assembly of the $\mathrm{S}$. lycopersicoides transcriptome Currently, a reference genome sequence is not available for S. lycopersicoides and a very limited number of nucleotide sequences are deposited in GenBank for this organism. Thus, to elucidate mechanisms of resistance to necrotrophs and provide a novel sequence resource, 454 pyrosequencing was used to sequence the transcriptome of $S$. lycopersicoides leaves 24 and $48 \mathrm{~h}$ after inoculation with $B$. cinerea, as well as leaves collected immediately after inoculation $(0 \mathrm{~h})$ to provide a baseline for comparison. A total of 654,159 reads consisting of nearly $165 \mathrm{Mb}$ were obtained (Table 1). Over 550,000 of the reads were assembled into 13,008 contigs, which were then assembled into 11,916 isotigs and 10,255 isogroups. Isogroups corresponded to genes, while isotigs within an isogroup represented splice variants of the gene. To reduce overrepresentation of genes with multiple splice variants, read counts from each isotig within an isogroup were summed. A representative isotig from each isogroup and the remaining contigs that were not assembled into isotigs accounted for a total of 10,385 unigenes.

The BLASTx algorithm was used to distinguish unigenes of $S$. lycopercicoides from those of B. cinerea and to remove sequences from contaminating species (e.g. bacteria and viruses). Of the 10,385 unigenes, 382 did not match any sequence in the non-redundant protein sequences database (nr, NCBI) or matched contaminating organisms and were thus excluded from further analyses. Of the remaining 10,003 unigenes, 9,414 (94.1\%) had significant matches with sequences from plant species and were thus determined to be $S$. lyocpersicoides sequences, whereas 589 (5.9\%) were determined to be of fungal origin. Among the 9,414 unigenes determined to

Table 1 Summary of Roche 454 GS-FLX assembly of S. lycopersicoides transcriptome sequences

\begin{tabular}{lll}
\hline Metric & Sequence (n) & Bases (bp) \\
\hline Total reads & 654,159 & $164,925,531$ \\
Average read length & & 252 \\
Aligned reads & $554,524(84.77 \%)$ & $140,923,440(85.45 \%)$ \\
Average trimmed read length & & 254 \\
All contigs & 13,008 & $9,327,270$ \\
Average contig length & & 717 \\
Large contigs & 8,431 & $7,863,766$ \\
Average large contig length & & 932 \\
N50 large contig length & & 988 \\
Largest contig & & 4,469 \\
Isotigs & 11,916 & $1,0722,599$ \\
Average isotig length & & 899 \\
N50 isotig length & 1,041 \\
Largest isotig & 4,504 \\
\hline
\end{tabular}

be of plant origin, nearly $91 \%(8,566)$ were highly similar to genes from $S$. lycopersicum, which has a sequenced reference genome [38], and an additional 5\% (466) were highly similar to genes from other species of Solanaceae, including S. tuberosum, Nicotiana tobacum, and Capsicum annuum. The remaining 4\% (382) of S. lycopersicoides unigenes were most similar to sequences found in comparatively distant plant species, including $A$. thaliana, Medicago truncatula, and Populus trichocarpa. The high percentage of $S$. lycopersicoides unigenes matching sequences from other members of the Solanaceae validates the de novo assembly of the $S$. lycopersicoides transcriptome and indicates high levels of sequence conservation between $S$. lycopersicoides and related species.

\section{Cluster analyses reveal distinct patterns of gene expression in response to $\mathrm{B}$. cinerea}

Differentially expressed $S$. lycopersicoides unigenes (Additional file 1) grouped into four distinct clusters. Cluster 1 contained genes induced $24 \mathrm{~h}$ after inoculation with decreased expression thereafter (Figure 3 ). Cluster 2 contained genes induced $24 \mathrm{~h}$ after inoculation whose expression remained up-regulated (Figure 4). Cluster 3 represented genes whose expression increased continually throughout the time course (Figure 5), and Cluster 4 represented genes in S. lycopersicoides that were down-regulated in response to $B$. cinerea infection (Figure 6). To examine potential relationships between expression pattern and biological function, unigenes in each cluster were assigned gene ontology (GO) terms in three categories: biological processes, molecular functions and cellular components. However, this initial assignment of $\mathrm{GO}$ terms was too broad, resulting in hundreds of terms, and thus a GO slim analysis was performed. GO slim is a defined list of high-level GO terms that cover broad aspects of processes, functions, and components [39].

GO slim analyses revealed many similarities between clusters 1 and 2. The major GO slim terms for biological processes associated with cluster 1 were "transport", "generation of precursor metabolites and energy", and "response to stress" (Figure 3B), and the major GO slim terms for molecular function were "nucleotide binding" and "hydrolase activity" (Figure 3C). The major GO slim terms for cellular component were "chloroplast", "mitochondrion", and "plasma membrane" (Figure 3D). Similar to cluster 1, the major GO slim terms for biological processes associated with cluster 2 were "transport", "response to stress", and "generation of precursor metabolites and energy" (Figure 4B), and the major GO slim terms for molecular function were "protein binding", "hydrolase activity", and "nucleotide binding" (Figure 4C). The major GO slim terms for cellular component were "mitochondrion", "chloroplast", and "plasma membrane" 

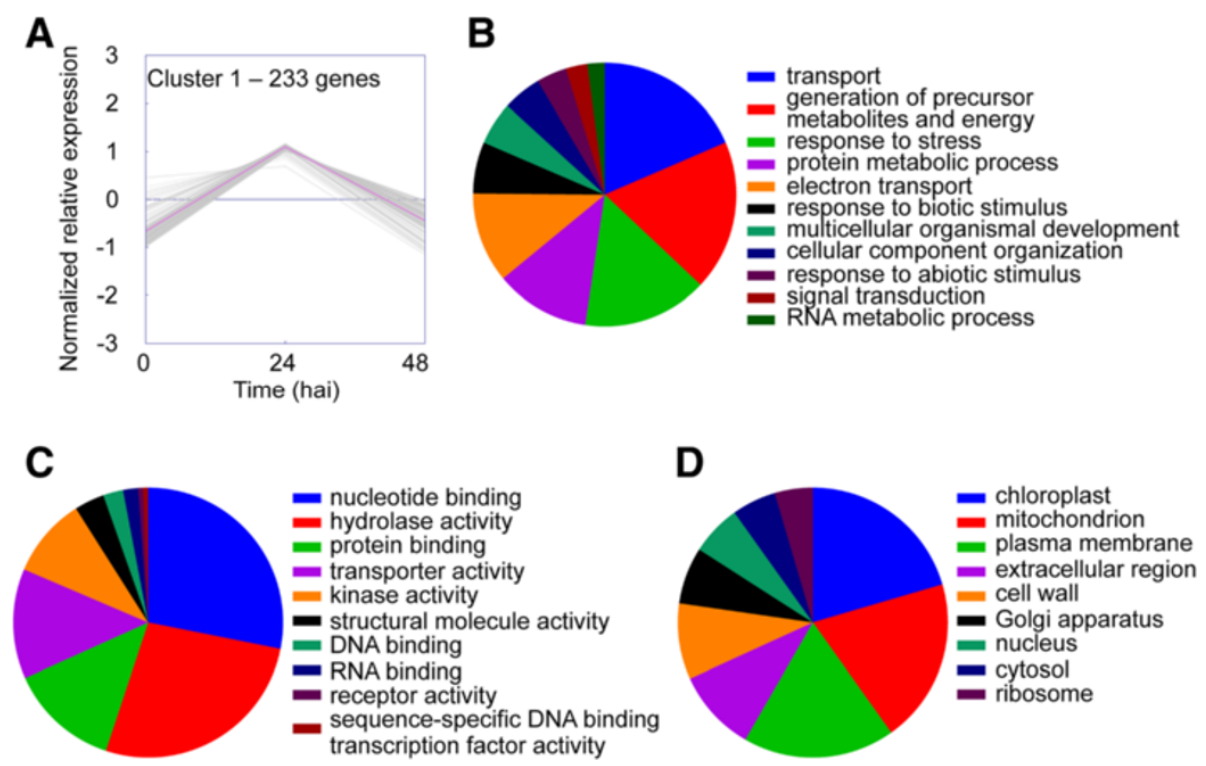

Figure $3 \mathrm{GO}$ terms associated with unigenes in expression cluster 1. (A) K-means clustering was used to visualize the expression pattern of unigenes in cluster 1. Expression increased rapidly from 0 to $24 \mathrm{~h}$ after inoculation then decreased to basal levels by $48 \mathrm{~h}$ after inoculation. Unigenes were annotated with GO terms corresponding to (B) biological processes, (C) molecular functions, and (D) cellular components. Pie charts represent the distribution of unigenes annotated with each $\mathrm{GO}$ term.

(Figure 4D). The similarities between biological processes, molecular functions, and cellular components for clusters 1 and 2 suggest that these two groups of genes are involved in similar responses to $B$. cinerea.

For cluster 3, GO slim terms were substantially different than clusters 1, 2, or 4. Specifically, the major GO slim terms for biological processes associated with cluster 3 were "response to stress", "protein metabolic process", "signal transduction", and "electron transport" (Figure 5B), and the major GO slim terms for molecular function were "hydrolase activity", "protein binding", and "nucleotide binding" (Figure 5C). The major GO slim
A

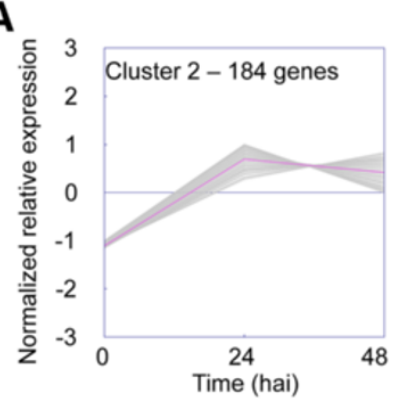

C

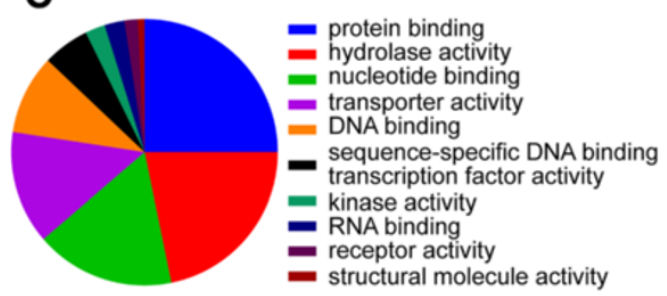

B

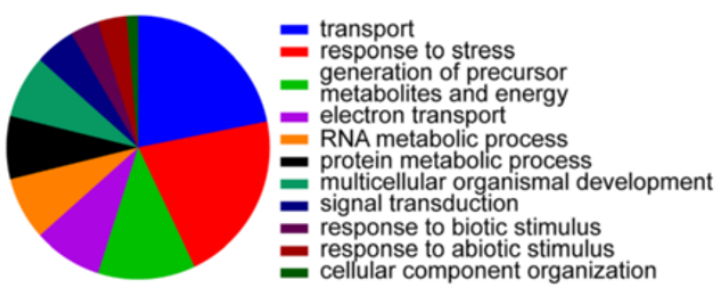

D

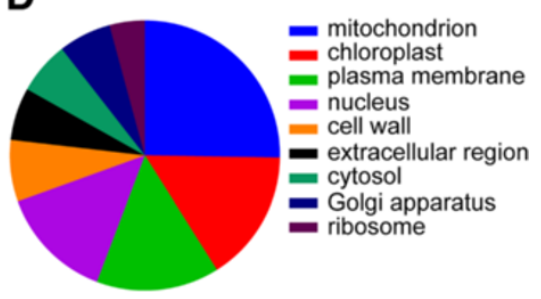

Figure 4 GO terms associated with unigenes in expression cluster 2. (A) K-means clustering was used to visualize the expression pattern of unigenes in cluster 2. Expression increased rapidly from 0 to $24 \mathrm{~h}$ after inoculation then plateaued. Unigenes were annotated with $\mathrm{GO}$ terms corresponding to (B) biological processes, (C) molecular functions, and (D) cellular components. Pie charts represent the distribution of unigenes annotated with each GO term. 

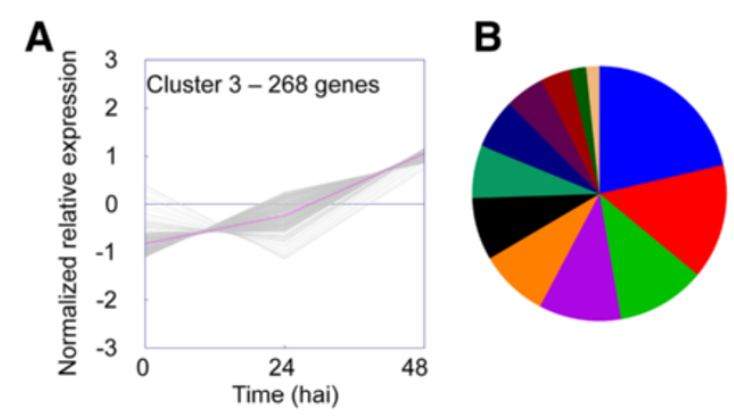
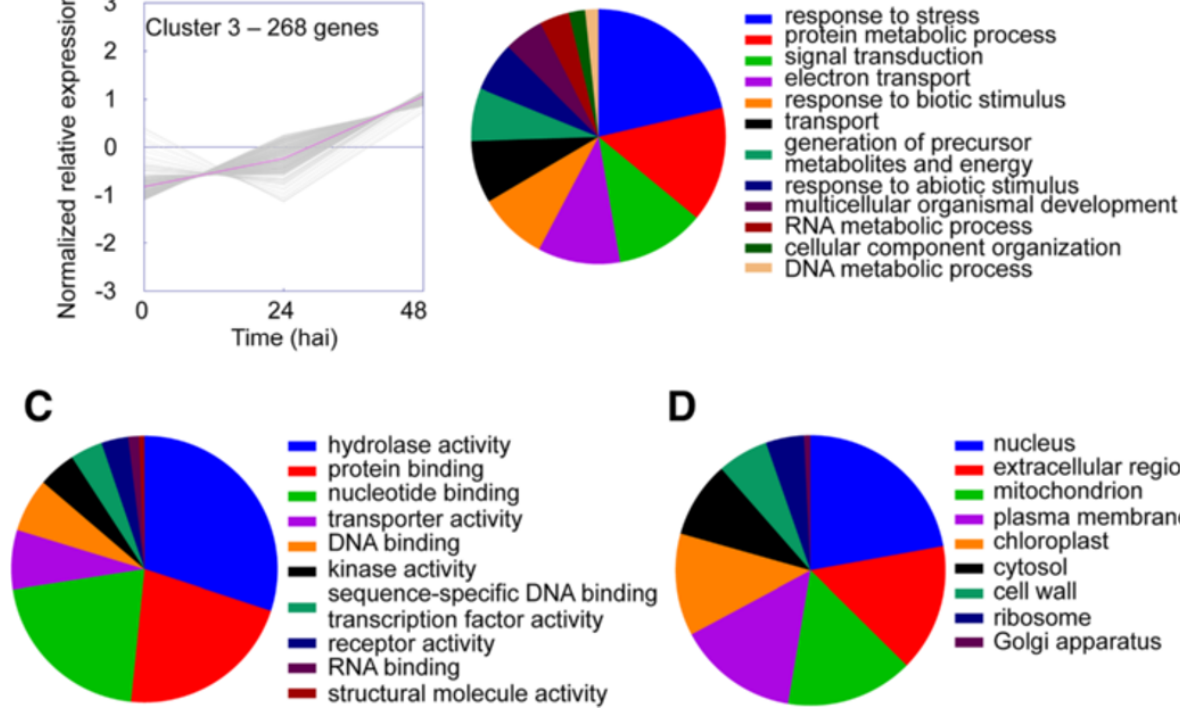

- RNA metabolic proces

- DNA metabolic process

\begin{abstract}
Figure $\mathbf{5}$ GO terms associated with unigenes in expression cluster 3. (A) K-means clustering was used to visualize the expression pattern of unigenes in cluster 3. Expression increased continually from 0 to $48 \mathrm{~h}$ after inoculation. Unigenes were annotated with $\mathrm{GO}$ terms corresponding to (B) biological processes, (C) molecular functions, and (D) cellular components. Pie charts represent the distribution of unigenes annotated with each GO term.
\end{abstract}

terms for cellular component were "nucleus", "extracellular region", and "mitochondrion" (Figure 5D). The induction of cluster 3 genes after pathogen attack is consistent with induced defense responses, however, the substantial differences in major GO slim terms in cluster
3 as compared to clusters 1 and 2 may reflect distinctly separate mechanisms of defense.

Cluster 4 contained the most pronounced differences in GO slim terms among the four clusters. The major GO slim terms for biological processes associated with
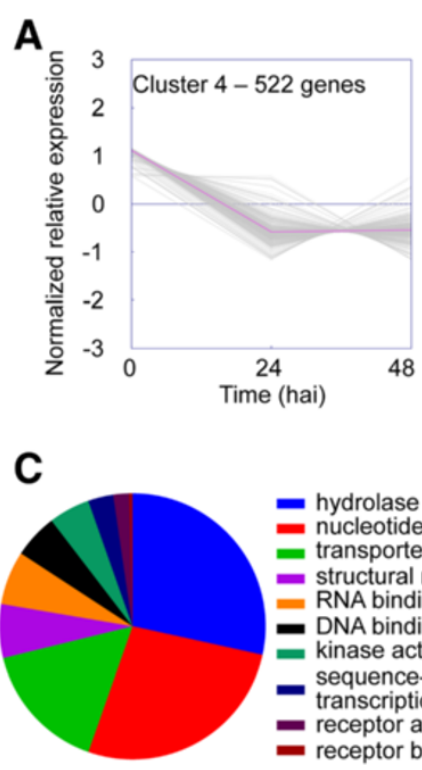

B

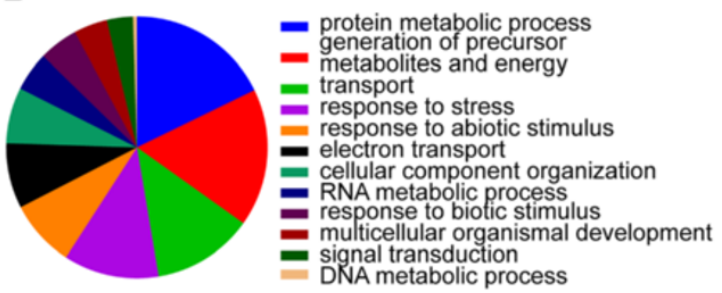

D

- hydrolase activity

- nucleotide binding

- structural molecule activity

- RNA binding

- DNA binding

- kinase activity

sequence-specific DNA binding

- transcription factor activity

- receptor activity

- receptor binding

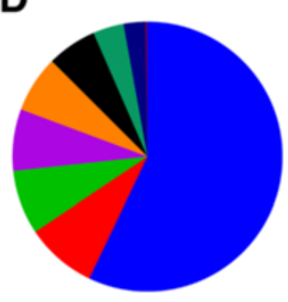

- chloroplast

nucleus

- extracellular region

- plasma membrane

- mitochondrion

- ribosome

- cell wall

- cytosol

- Golgi apparatus

Figure 6 GO terms associated with unigenes in expression cluster 4. (A) K-means clustering was used to visualize the expression pattern of unigenes in cluster 4. Expression decreased from 0 to $48 \mathrm{~h}$ after inoculation. Unigenes were annotated with $\mathrm{GO}$ terms corresponding to (B) biological processes, (C) molecular functions, and (D) cellular components. Pie charts represent the distribution of unigenes annotated with each GO term. 
this cluster were "protein metabolic process", "generation of precursor metabolites and energy", "transport", and "response to stress" (Figure 6B), and the major GO slim terms for molecular function were "hydrolase activity" and "nucleotide binding" (Figure 6C). The major GO slim term for cellular component was "chloroplast" (Figure 6D). Overall, these results strongly suggest a rapid and intense suppression of primary metabolism upon challenge with $B$. cinerea, presumably due to resource reallocation to defense responses.

To complement the broad overview of the processes, functions, and components provided by GO slim terms, an enrichment analysis identified individual GO terms that were significantly over-represented in each cluster of unigenes (Figure 7). In cluster 1, 13 biological processes were significantly enriched, all of which were associated with the production of ATP. Peak expression of genes involved in ATP biosynthesis at $24 \mathrm{~h}$ after inoculation is consistent with the rapid conversion of precursor metabolites to energy upon pathogen attack. Conversely, two terms were enriched in cluster 2, with one unigene assigned to each term. The two GO terms enriched in cluster 2 are broad and somewhat uninformative; "oxidation-reduction process" and "metal ion transport" could be involved in many aspects of metabolism. Additionally, the small number of significantly over-represented GO

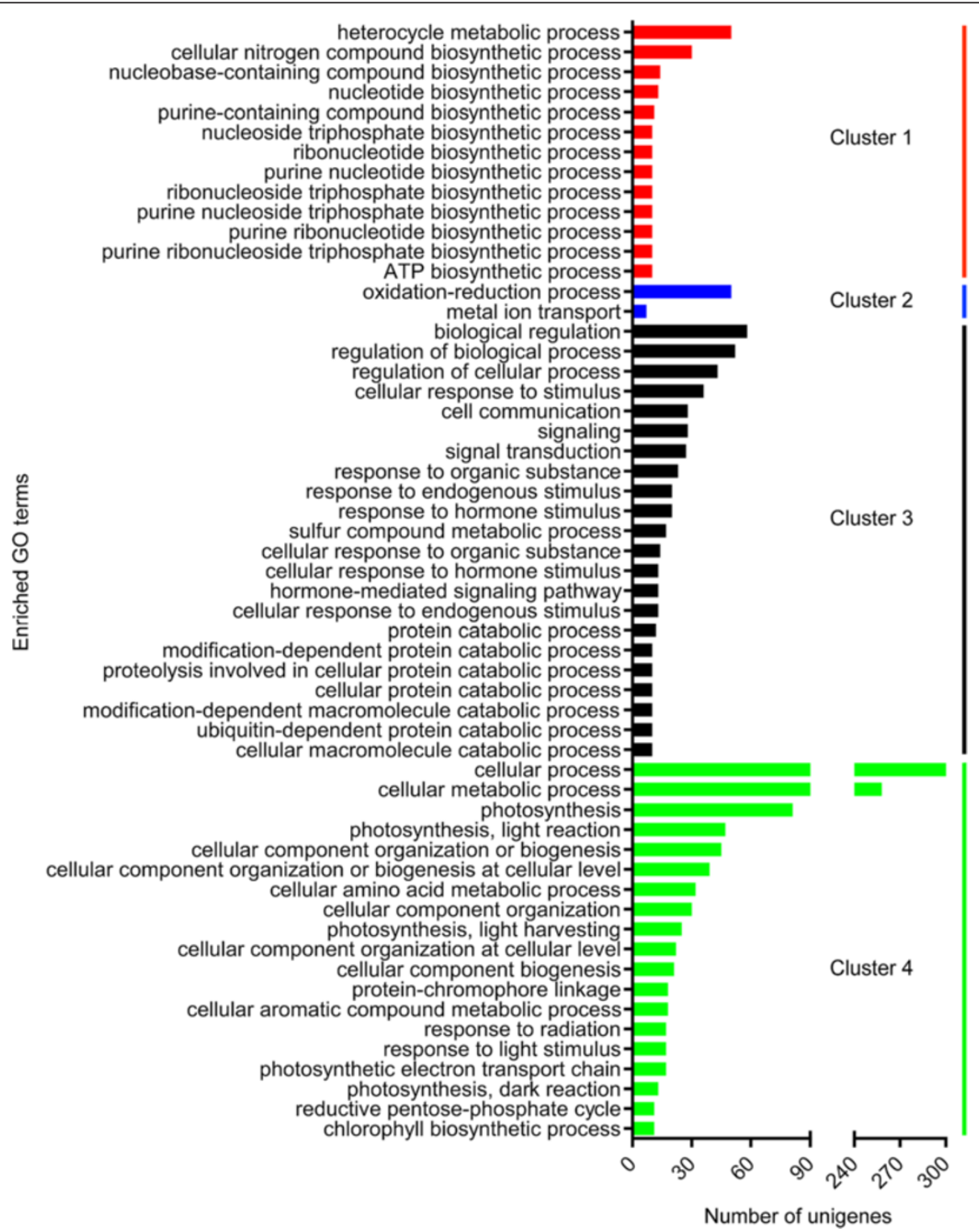

Figure 7 Enrichment analysis of biological processes associated with each expression cluster. Enrichment analysis was performed to determine which biological processes were present at significantly higher frequency in cluster 1 (red bars), cluster 2 (blue bars), cluster 3 (black bars), and cluster 4 (green bars). The X-axis indicates the number of unigenes annotated with a given GO term. 
terms in cluster 2 suggests that unigenes in this cluster share similar overall functional annotation with other clusters. Cluster 3 was enriched with terms involved in "signaling", "protein degradation", and "response to stimuli". Enrichment of the term "signaling" is in agreement with the findings of Windram et al. [40], who showed that genes involved in signaling were rapidly upregulated in Arabidopsis as early as 16 hours after inoculation with B. cinerea. Furthermore, De Cremer et al. [41] demonstated that genes involved in signaling were upregulated in lettuce, 48 hours after inoculation with B. cinerea. Enrichment of these terms indicates that $S$. lycopersicoides mounts an early and sustained signaling response to infection by $B$. cinerea, as would be expected by the requirement for continual containment of a necrotrophic fungal pathogen. Cluster 4 was significantly enriched with multiple terms relating to photosynthesis, which is consistent with the rapid down-regulation of genes involved in photosynthesis in $B$. cinerea infected plants described by Berger et al. [42], Windram et al. [40], and De Cremer et al. [41]. Taken together, the cluster analyses provided insight into potential linkages between gene expression patterns and biological responses underlying resistance to B. cinerea in S. lycopersicoides.

\section{Comparative expression analysis of selected genes in}

\section{S. lycopersicoides and S. Iycopersicum}

To confirm the RNA-seq data from S. lycopersicoides and provide insight into differential transcriptional responses to B. cinerea in S. lycopersicum, six differentiallyexpressed genes (induced and suppressed in response to B. cinerea) were assessed in S. lycopersicoides and $S$. lycopersicum with quantitative PCR (qPCR). Four genes reported to be involved in resistance to necrotrophs (pathogenesis-related protein 1 (PR1) [43,44], a beta1,3-glucanase (glucanase) [44], a subtilisin-like protease [45], and glutathione S-transferase $[46,47]$ ) were chosen to represent defense-related genes induced upon attack by $B$. cinerea, and two genes involved in photorespiration (ribulose-1,5-bisphosphate carboxylase (Rubisco) small subunit and glycolate oxidase 1) were chosen to represent down-regulated genes. Upon challenge with $B$. cinerea, potentially important differences in expression profiles of the selected genes were observed in comparisons between S. lycopersicum and S. lycopersicoides. Among the genes induced during infection by B. cinerea in S. lycopersicoides, several differences in induction patterns were observed in S. lycopersicum. As an example of delayed induction, expression of PR1 rapidly increased in S. lycopersicoides from 0 to $24 \mathrm{~h}$ after inoculation as observed in the RNA-seq analysis, whereas induction in S. lycopersicum was not observed until $48 \mathrm{~h}$ after inoculation, at which time expression levels were comparable to S. lycopersicoides (Figure 8A).
As an example of delayed and reduced induction, expression of glucanase continually increased in response to $B$. cinerea in S. lycopersicoides as previously determined through transcriptomics, but the induction in tomato was consistently later and at lower levels than observed in S. lycopersicoides (Figure 8B). Expression of a subtilisin-like protease in S. lycopersicum provided an even more pronounced example of delayed and reduced induction, whereas the induction pattern observed in $S$. lycopersicoides was consistent with results from RNA-seq analyses (Figure 8C). However, at least some genes were similarly induced in S. lycopersicoides and $S$. lycopersicum in response to $B$. cinerea, as evidenced by glutathione S-transferase (Figure 8D). Additionally, expression of the genes involved in photorespiration, particularly Rubisco, dropped more dramatically in $S$. lycopersicoides than in S. lycopersicum (Figure 8E, F), which suggests that the speed at which photosynthesis is suspended after pathogen attack may play a critical role in defense-related resource reallocation.

\section{Metabolic pathway analysis}

For metabolic pathway mapping, KEGG (Kyoto Encyclopedia of Genes and Genomes) orthology (KO) identifiers were assigned throughout the four differentially expressed clusters of $S$. lycopersicoides genes which were then mapped individually to pathway maps in the KEGG database. This process identified potential shunts in metabolism resulting from $B$. cinerea infection, the most striking example of which was in the pathway for terpenoid backbone biosynthesis (Additional file 2). Specifically, several genes in the 2-C-methyl-D-erythritol 4-phosphate (MEP) pathway were suppressed in response to $B$. cinerea, while genes in the mevalonate pathway were induced. The mevalonate pathway is used by plants for the biosynthesis of sesquiterpene phytoalexins [48-50], while the MEP pathway is localized in plastids and is the pathway for the production of structurally distinct terpenoids including carotenoids and the phytol chain of chlorophyll [50]. Recently, the MEP pathway was also implicated in stress response [51,52]. The MEP pathway acts as stress sensor and, through the biosynthesis of retrograde signaling molecules, an inducer of stress response genes. However, accumulation of methylerythritol cyclodiphosphate (MEcPP), a stress-induced, retrograde signaling molecule produced via the MEP pathway, is associated with abiotic stress and results in increased resistance to biotrophs and enhanced susceptibility to $B$. cinerea [51]. Thus, the coordinated change in gene expression from the MEP pathway to the mevalonate pathway, in $S$. lycopersicoides during defense against $B$. cinerea, is consistent with a shift away from abiotic stress response and biotrophic pathogen resistance and with 

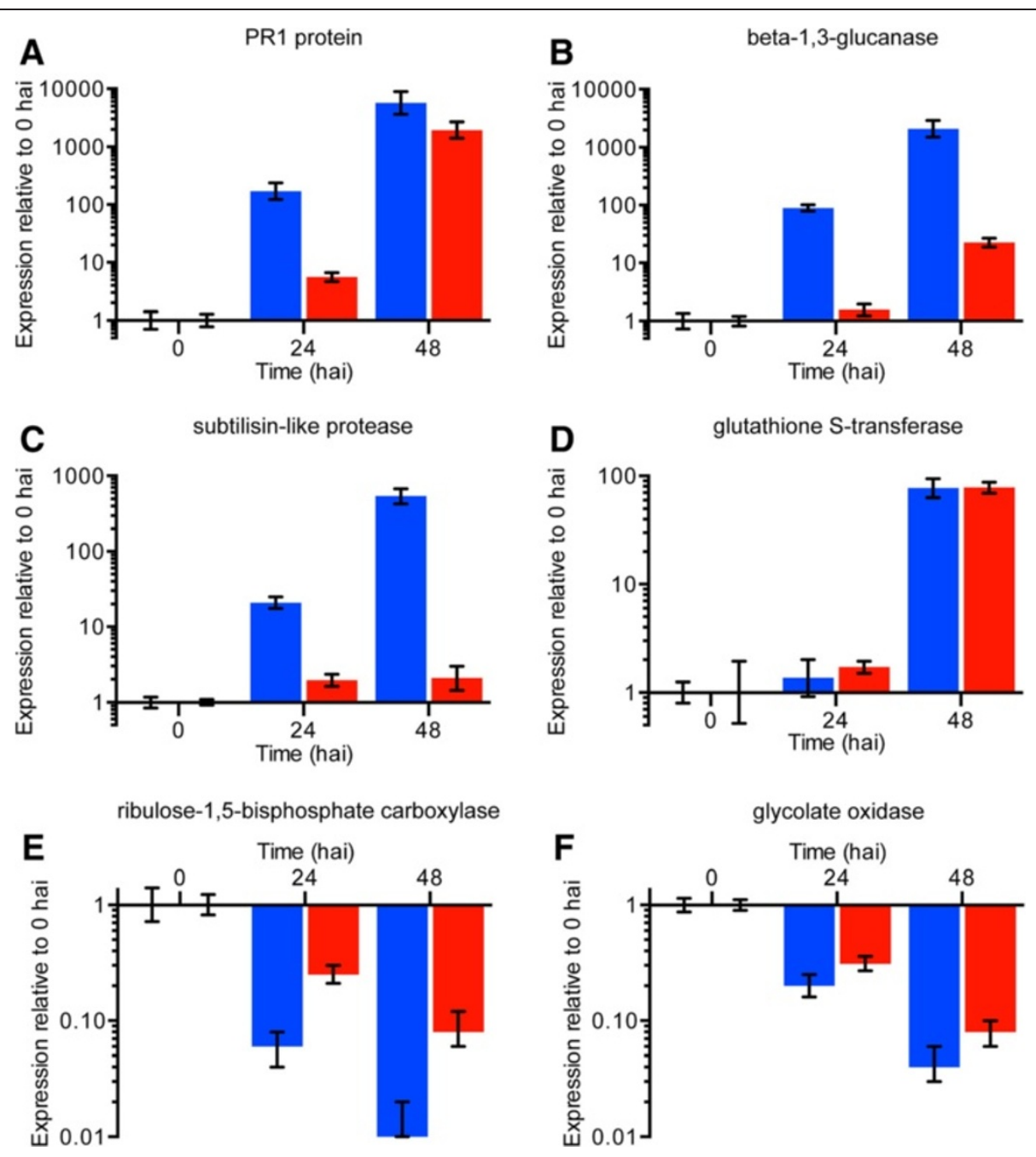

Figure 8 Relative expression of selected genes measured by qPCR. Different patterns of gene expression were observed for S. lycopersicoides and S. Iycopersicum inoculated with B. cinerea. Induction of (A) a PR1 protein-encoding gene was delayed in S. Iycopersicum compared to S. Iycopersicoides, but expression at 48 hours after inoculation (hai) was comparable in both Solanum species. Induction of (B) a beta-1,3-glucanaseencoding gene and (C) a subtilisin-like protease-encoding gene was also delayed in S. lycopersicum; however, expression at 48 hai was reduced compared to S. Iycopersicoides. Induction and expression of (D) a glutathione S-transferase-encoding gene were comparable between S. Iycopersicum and S. Iycopersicoides. Expression of (E) a ribulose-1,5-bisphosphate carboxylase-encoding gene and (F) a glycolate oxidase-encoding gene decreased over time in both S. Iycopersicum and S. lycopersicoides, but the rate and overall reduction of expression was greater in S. lycopersicoides. Genes were selected for qPCR analysis based on expression and predicted role in pathogen defense. Blue bars represent expression of genes in S. Iycopersicoides relative to timepoint 0 . Red bars represent expression of genes in $S$. lycopersicum relative to timepoint 0 .

the increased phytoalexin biosynthesis observed in other solanaceous plants $[48,53]$.

\section{Identification of B. cinerea genes highly expressed during infection}

GO slim analyses were performed on the 589 unigenes determined to be of fungal origin (Additional file 3 ). The biological processes most represented in B. cinerea were "catabolic process", "translation", "carbohydrate metabolic process", and "generation of precursor metabolites and energy" (Figure 9A). The abundance of unigenes associated with catabolic processes and carbohydrate metabolic processes is suggestive of the induction of cell wall degrading enzymes, while the presence of numerous unigenes associated with translation and energy generation is consistent with rapid colonization of S. lycopersicoides by B. cinerea. Furthermore, the term "secondary metabolic process" suggests a prominent role for the biosynthesis of phytotoxic compounds during pathogenesis. The molecular functions associated with $B$. cinerea infecting $S$. lycopersicoides are consistent with the biological processes. The most represented function was "nucleotide binding" (Figure 9B), which suggests widespread and dynamic reprogramming of the fungal transcriptome 


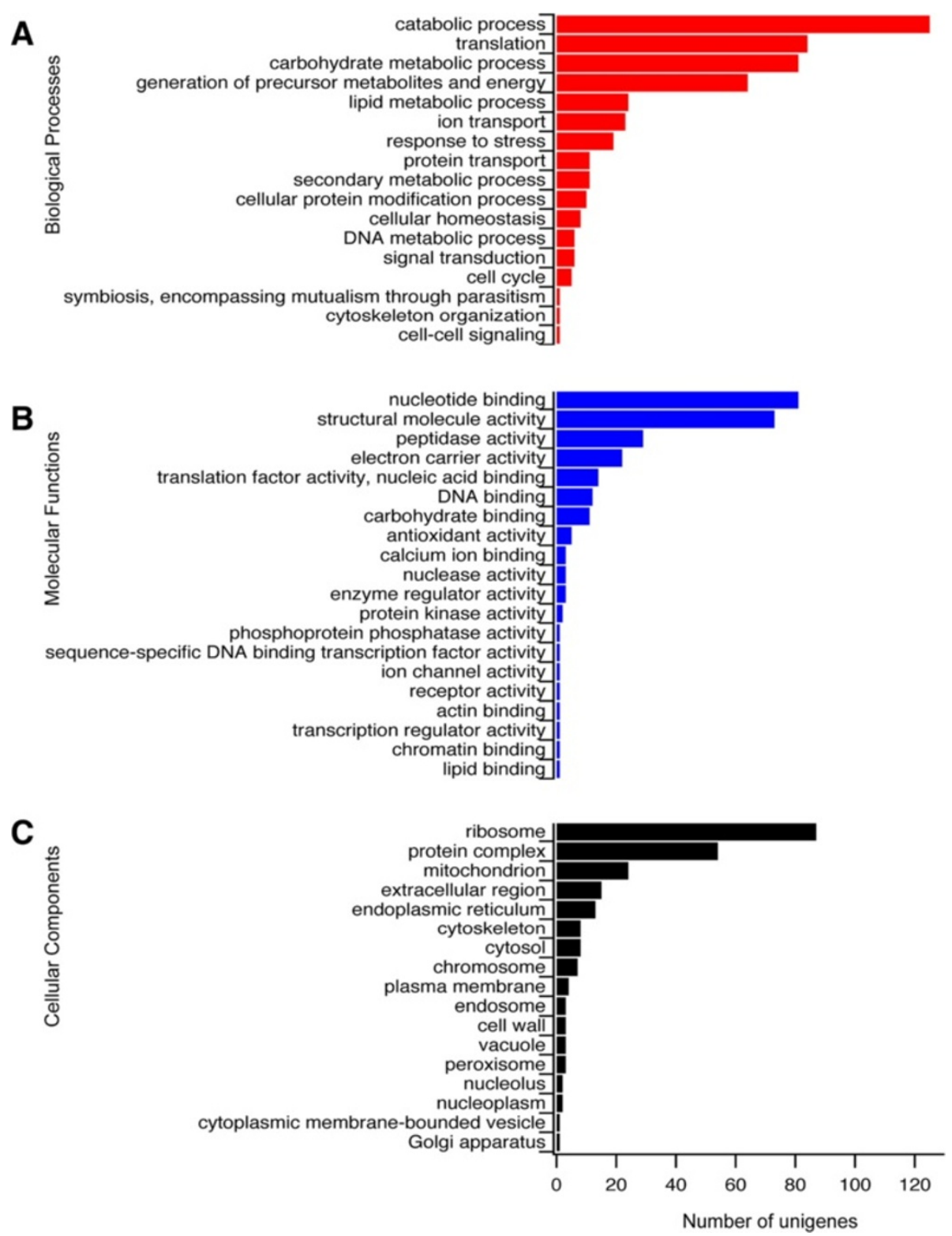

Figure $9 \mathrm{GO}$ analysis of $B$. cinerea unigenes expressed during infection of S. lycopersicoides. Fungal unigenes were annotated with $\mathrm{GO}$ terms corresponding to (A) biological processes (red bars), (B) molecular functions (blue bars), and (C) cellular components (black bars). The X-axis indicates the number of unigenes annotated with a given $\mathrm{GO}$ term.

required to sustain pathogenesis and counteract host defense responses. Additionally, the enrichment of the term "structural molecule activity" is consistent with the activation of diverse genes involved in fungal growth. Given the presence of numerous genes with predicted functions associated with protein synthesis in $B$. cinerea during early infection of $S$. lycopersicoides, it is not surprising that the two most represented cellular components were "ribosome" and "protein complex". Furthermore, representation of the term "mitochondrion" was enriched, as would be expected in a fungus displaying intense metabolic activity during pathogenesis.
For each B. cinerea gene identified, expression profiles were analyzed throughout the infection time course. Very few sequences from $B$. cinerea were detected at the $0 \mathrm{~h}$ time point (immediately after inoculation with fungal conidia), and thus expression of all fungal unigenes were significantly higher at 24 and $48 \mathrm{~h}$ after inoculation. Interestingly, genes implicated in pathogenesis and necrosis were abundantly expressed 24 and $48 \mathrm{~h}$ after inoculation, such as genes encoding an endopolygalacturonase (Bcpg1) demonstrated to play a role in virulence on tomato $[4,54]$, a superoxide dismutase $(b c s o d 1)$ required for lesion expansion on Phaseolus vulgaris [55], and two 
cytochrome p450 monooxygenases (BcBOT1 and $B c B O T 2)$ required for biosynthesis of the phytotoxin, botrydial [56,57] (Additional file 3). The observed induction patterns of toxin biosynthetic genes, genes encoding cell wall degrading enzymes, and genes involved in scavenging reactive oxygen species indicate that $B$. cinerea actively induces necrosis in its host as early as $24 \mathrm{~h}$ after contact. In addition to genes involved in disease development, genes related to growth and energy production were among the most highly expressed in $B$. cinerea during pathogenesis, such as elongation factor 1 alpha and glyceraldehyde 3-phosphate dehydrogenase (Additional file 3). Although the primary objective of this study was to generate a sequence-based resource to identify genes in $S$. lycopersicoides involved in resistance to $B$. cinerea, the dataset created could assist efforts to identify novel genes in B. cinerea involved in early stages of infection.

\section{Discussion}

Previous research has demonstrated that S. lycopersicoides is tolerant to abiotic stresses such as cold injury and nutrient deficiency, and is simultaneously resistant to diverse pathogens that are problematic on tomato, including viruses (tomato mosaic virus and cucumber mosaic virus), oomycetes (Phytophthora parasitica), and fungi (Cladosporium fulvum and Botrytis cinerea) [30,31,58]. In this study, S. lycopersicoides was confirmed to express resistance against $B$. cinerea, and newly found to be resistant to A. solani. S. lycopersicoides is a wild solanaceous species native to the Andean region of Chile and Peru, which is the center of diversity for many Solanum species [31,58], and thus has likely evolved robust resistance responses to broad-range and hostspecific necrotrophic fungal pathogens. Because S. lycopersicoides is closely related to and can be crossed with tomato [31], introgression lines have been created in which chromosomal segments from S. lycopersicoides have been incorporated into the genome of cultivated tomato [34]. Introgression lines provide a powerful resource for future determination of genes conferring resistance to B. cinerea and/or A. solani. Thus, genetic compatibility with cultivated tomato, a high level of resistance to necrotrophs, and availability of genetic resources make $S$. lycopersicoides an ideal source of novel genes to be harnessed through transgenic or conventional breeding techniques to improve the resistance of tomato to necrotrophic pathogens. By sequencing the transcriptome of $S$. lycopersicoides during early infection by $B$. cinerea, this work provides a novel and important resource for future work.

The molecular basis of resistance against $B$. cinerea and $A$. solani is not known. In general, plant resistance mechanisms to necrotrophic pathogens are believed to be distinct from or antagonistic to plant responses to biotrophs, which is consistent with their contrasting pathogenesis strategies $[7,8,11]$. Multiple examples signify differences in host resistance to these groups of pathogens [7,59]. R-gene mediated resistance (e.g., effector triggered immunity, ETI) is normally activated upon recognition of race specific effector proteins by R-proteins and confers resistance to biotrophic pathogens [59]. ETI is a widespread and strong form of resistance but is not known to be effective against necrotrophs. Indeed, R-gene mediated susceptibility to necrotrophs has been documented [60-62]. The major manifestation of ETI is often the hypersensitive response (HR), a form of cell death, is central to plant resistance to biotrophs but promotes susceptibility to necrotrophs [6]. Production of reactive oxygen species (ROS) orchestrates HR and modulates resistance to biotrophs but may act as a virulence factor in some necrotrophs such as $B$. cinerea [63]. The signaling molecule salicylic acid (SA) promotes resistance to biotrophs but actually suppresses defense against necrotrophs $[64,65]$. Systemic acquired resistance (SAR) is an SA-dependent resistance response that protects plants against many biotrophic pathogens [66-70] whereas its efficacy in conferring resistance to necrotrophs is unclear. Arabidopsis mutants impaired in SAR show normal resistance to necrotrophic fungi [67], whereas mutants that constitutively express SAR are more susceptible [71,72]. Systemic and local defenses mediated by ethylene (ET) and jasmonate (JA) are required for resistance to necrotrophic pathogens $[67,73]$, whereas SA is generally associated with resistance to biotrophic infection $[66,69,74,75]$. Although the scientific literature is replete with examples of antagonistic interactions between pathways mediated by SA and JA/ET in Arabidopsis, such interactions are not studied in other plant systems including tomato [7,76-78]. These and many other examples suggest defense strategies that have evolved to guard plants against necrotrophs that operate distinctly or by antagonizing other responses.

The regulatory mechanism involved in host responses to broad-host necrotrophs such as B. cinerea is slowly emerging, predominantly from studies in Arabidopsis, but also to a limited extent in tomato. Diverse and unique processes that specifically mediate basal resistance to necrotrophs without any effect on biotrophic pathogens have been described. The tomato TPK1b and AIM1 function in defense against necrotrophic fungi with no role in resistance to other obligate or biotrophic pathogens [79,80]. TPK1b function in defense is through modulation of ET signaling while AIM1 functions in ABA dependent immune responses. Many transcription-factors (TFs) that mediate defense response to necrotrophic infection have been identified through microarray and genetic analysis [46]. Among these, WRKY33, ZFAR1, ERF1 and ERF104, MYB, AS1, and HD-Zip homeodomain 
proteins are required for resistance to necrotrophic fungi, underlining the importance of transcriptional regulation in defense to these pathogens [46,81-86]. The role of transcriptional regulation is further reinforced by the recent discovery of the immune response functions of subunits of the transcriptional coactivator Mediator complex as specific regulators of plant immune responses to necrotrophs $[87,88]$. Genetic evidence linking chromatin modifications such as histone ubiquitination, methylation, and deacetylation and chromatin remodeling to defense responses to necrotrophs due to their effects on expression of genes encoding various plant defense responses have been established [88-91]. Components of the plant cell wall and cuticle, predominantly considered physical barriers to infection, have found new and unexpected defense roles with mutants harboring defects in cuticle and cell wall components becoming more resistant to necrotrophs, thus revealing the dependence of virulence in necrotrophic fungi on critical host components [78,92-96].

While the mechanisms of resistance to necrotrophic fungal pathogens are not fully understood, the ability of S. lycopersicoides to rapidly shift metabolism from photosynthesis to the production of resistance associated proteins and secondary metabolites appears to be a key factor for resistance to $B$. cinerea. Several classes of genes including pathogenesis related protein genes (PR1), protease genes (subtilisin) and glucanase genes (beta-1,3-glucanase) are rapidly and strongly induced in $S$. lycopersicoides in response to B. cinerea infection. However, this increased expression of defense related genes coincides with a reduced expression of genes involved in photorespiration such as ribulose-1,5-bisphosphate carboxylase and glycolate oxidase. This metabolic shunt occurs in S. lycopersicum as well as S. lycopersicoides, but at a slower rate and to less dramatic levels. Furthermore, metabolic pathway analysis in S. lycopersicoides demonstrates a shift within terpenoid biosynthesis away from the plastidic MEP pathway involved in pigment biosynthesis [97] to the mevalonate pathway involved in the synthesis of phytoalexins [98]. Taken together, these results point to a global change in metabolism that allows $S$. lycopersicoides to more effectively react to infection by necrotrophs.

In addition to identifying genes and metabolic changes associated with resistance to necrotrophs, this research has uncovered a number of fungal genes that are highly expressed during the early stages of infection of S. lycopersicoides. Several highly expressed genes, such as elongation factor 1 alpha and glyceraldehyde 3-phosphate dehydrogenase, are not surprising due to their fundamental roles in fungal growth. However, several genes coding hydrolytic enzymes, including an endo-polygalacturonase and an aspartic protease, as well as other genes, such as a cytochrome p450 monooxygenase required for the biosynthesis of phytotoxic secondary metabolites, were also induced. These findings demonstrate the potential value of the transcriptomic data generated in this research for identifying novel genes required for necrotrophy.

Another distinct value of this RNA-seq dataset is that it represents the first large-scale public sequence resource for S. lycopersicoides. Analogous to an EST sequencing experiment before the advent of next-generation sequencing, this study provides a dataset of species-specific sequence data for future validation of genome sequencing and identification of genes (based on homology as well as expression pattern) for functional characterization. Prior to this study, little information was available regarding molecular mechanisms of resistance in S. lycopersicoides. Based on the analyses of fungal growth and changes in host gene expression during the resistance response, a key mechanism of resistance appears to be constraining the growth of the pathogen through rapid and extensive reprogramming of the $S$. lycopersicoides transcriptome. In this study, numerous candidate defense-related genes were identified through clustering analyses; extensive functional characterization will be required to determine the genetic regulatory network underlying resistance.

It is important to note that RNA samples were pooled prior to sequencing in our approach, and thus the expression values obtained from sequencing the $S$. lycopersicoides transcriptome are indicative of qualitative trends in expression rather than exact quantitative measures of gene expression. Replicates were pooled to maximize the number of biological conditions evaluated within the experiment, and clustering analyses were performed to assess changes in expression. Sequencing separate replicates would have provided certain advantages, particularly with respect to calculating more precise digital expression values with greater rigor. However, pooled RNA samples are inherently normalized; expression is averaged among individuals, and thus this approach reduces the impact of isolated variability among individuals within a treatment. Similarly, pooled samples have proven useful to analyze differential expression in various other systems, including plants [99], animals [100,101], and fungi $[102,103]$.

Research into mechanisms of plant resistance to necrotrophic fungal pathogens has been generally limited. A majority of studies, to date, have focused on Arabidopsis. Tomato, as a model for studying necrotrophic interactions, has been problematic due to the universal susceptibility of all tested varieties to important necrotrophs including $B$. cinerea. However, the availability of a resistant species that can be crossed with tomato provides a unique opportunity to study plant/necrotroph interactions in a commercially important crop species. Furthermore, the availability of this transcriptome data could be effectively 
used in conjunction with existing tomato lines containing defined introgressions of S. lycopersicoides chromosomal segments to identify features of the $S$. lycopersicoides genome that are crucial for resistance to necrotrophs.

\section{Conclusions}

Tomato (Solanum lycopersicum), one of the world's most important vegetable crops, is highly susceptible to necrotrophic fungal pathogens such as Botrytis cinerea and Alternaria solani. Improving resistance through conventional breeding has been hampered by a shortage of resistant germplasm and difficulties in introgressing resistance into elite germplasm without linkage drag. Screening of wild Solanum species uncovered a relative of tomato, $S$. lycopersicoides, that is resistant to both $B$. cinerea and A. solani. Transcriptome analysis of $S$. lycopersicoides at 0 , 24 , and 48 hours after inoculation with $B$. cinerea revealed possible mechanisms for resistance to necrotrophs and identified genes from $B$. cinerea that are induced during pathogenesis. Taken together, this research provides new insight into resistance to necrotrophs while providing a novel sequence resource for $S$. lycopersicoides.

\section{Methods}

\section{Plant materials and fungal isolates}

Accessions: LA0490 (S. lycopersicum, VF-36), LA2951 (S. lycopersicoides), LA3475 (S. lycopersicum, M-82), LA1932 (S. chilense), LA1708 (S. arcanum), LA1589 (S. pimpinellifolium), LA0716 (S. pennellii), LA0317 (S. galapagense), LA1777 (S. habrochaites), and LA1223 (S. habrochaites f. glabratum, Chimbalo) were developed by and/or obtained from the UC Davis/C.M. Rick Tomato Genetics Resource Center and maintained by the Department of Plant Sciences, University of California, Davis, CA 95616. S. lycopersicum cv. Bradley was obtained from the New England Seed Company (http://www.neseed.com/); Hartford, CT 06120). S. lycopersicum cv. Castlemart II was kindly provided by Greg Howe (Michigan State University). $B$. cinerea (B05.10) was maintained on $2 \mathrm{xV} 8$ agar in the dark at $25^{\circ} \mathrm{C}$ and $A$. solani (AR18, isolated from tomato in Arkansas) was maintained on V8 agar.

\section{Pathogen inoculation}

Wild relatives of tomato and tomato cultivars were evaluated for their resistance to B. cinerea and A. solani by inoculating detached leaves. Inoculum of $B$. cinerea was prepared by cutting blocks of agar from 10-day-old cultures and agitating in 1\% Sabouraud maltose broth (SMB). Conidia were separated from agar and mycelium by filtration through sterile cheesecloth. The spore concentration was checked with a hemacytometer and adjusted to $5 \times 10^{5} / \mathrm{ml}$ with SMB. Detached leaves of $S$. lycopersicum and $S$. lycopersicoides (4 each per time point) were inoculated with 8 drops ( $5 \mu \mathrm{l}$ each) of the $B$. cinerea spore suspension and placed on sterile filter paper moistened with sterile $\mathrm{H}_{2} \mathrm{O}$ in a covered petri dish. Inoculated leaves were incubated in a growth chamber with a $12 / 12$ light/dark cycle at $21^{\circ} \mathrm{C}$ day and $18^{\circ} \mathrm{C}$ night temperatures. Lesion diameters were measured daily and a subset of leaves was collected each day for RNA extraction and ergosterol analysis. Due to low sporulation of the pathogen, mycelial fragments of $A$. solani at a concentration of $400 \mathrm{mg} / \mathrm{mL}$ was used for drop inoculation; otherwise conditions were similar to those described for B. cinerea.

\section{Quantification of ergosterol by HPLC}

Inoculated leaves were frozen in liquid nitrogen and ground to a fine powder with a mortar and pestle. Ergosterol was then extracted from ground leaf tissue (150-550 mg) and analyzed by high pressure liquid chromatography as described by de Sio et al. [104] with minor adjustments. Briefly, ground leaves were added to $2.0 \mathrm{ml}$ of 2:1 chloroform:methanol and extracted overnight. The extract was filtered through a $0.2 \mu \mathrm{m}$ filter and $20 \mu \mathrm{l}$ was injected onto a $25 \mathrm{~mm}$ C18 column (phenomenex, Torrance, CA). The mobile phase consisted of $80 \%$ methanol in $\mathrm{H}_{2} \mathrm{O}$ (solvent $\mathrm{A}$ ) and $100 \%$ dichloromethane (solvent $\mathrm{B}$ ). The gradient program consisted of a linear increase from $0 \%$ to $50 \%$ solvent B over 20 minutes followed by 15 minutes at $50 \%$ solvent B. Ergosterol was measured based on absorbance at $282 \mathrm{~nm}$ and was quantified based on comparison of peak area to pure standards (Alfa Aesar, Ward Hill, MA). Ergosterol concentration was then normalized to the mass of the extracted tissue and leaf mass.

\section{RNA extraction and CDNA synthesis}

Inoculated leaves were frozen in liquid nitrogen and ground with a mortar and pestle. Total RNA was extracted from the ground tissue with TRIzol Reagent (Life Technologies, Grand Island, NY) according to the manufacturer's instructions. RNA quantity and quality was determined with a NanoDrop spectrophotometer (Thermo Scientific, Wilmington, DE) and by visual inspection after electrophoresis. A total of $1 \mu \mathrm{g}$ of RNA from each sample was treated with RQ1 DNase (Promega, Madison, WI) according to the manufacturer's instructions. The DNase treated RNA $(1 \mu \mathrm{g})$ was used as template to generate cDNA with M-MLV Reverse Transcriptase (Promega, Madison, WI) according to the manufacturer's instructions.

\section{4 sequencing and data processing}

For transcriptome sequencing, S. lycopersicoides plants were spray inoculated with spores of $B$. cinerea at a concentration of $3 \times 10^{5} / \mathrm{ml}$. Total RNA was collected from inoculated leaves from 2 plants per time point at 0 hours, 24 hours, and 48 hours after inoculation. RNA from replicate leaf samples was pooled prior to sequencing. 
Conceptually, RNA pooling was performed as described by TJ Huth and SP Place [100], PA Olsvik, V Vikeså, KK Lie and EM Hevrøy [101] Library construction, sequencing, and de novo assembly were performed by the Purdue Genomics Core Facility (West Lafayette, IN). Read counts at each time point from individual isotigs within an isogroup were summed to reduce overrepresentation of genes with multiple splice variants. To identify unigenes from S. lycopersicoides and B. cinerea, as well as to remove contaminating sequences, Blast2GO (version 2.6.6) [105] was used to query the assembled unigenes against the $\mathrm{nr}$ database. The Audic and Claverie method [106] was used to identify plant unigenes that were differentially expressed between 0,24 , and 48 hours after inoculation with a false discovery rate of $<0.0033$. Kmeans clustering was performed on the differentially expressed plant genes with the genesis software (version 1.7.6) [107]. For K-means clustering, unigenes were assigned to one of four clusters. The basis for choosing four clusters was the closeness of fit of unigenes within each cluster, as well as the biological relevance of the expression patterns observed for each cluster. Blast2GO was used to functionally characterize unigenes within each plant cluster, as well as all fungal unigenes. InterProScan [108] was used to annotate unigenes with conserved protein domains. To identify GO terms that were enriched within each plant cluster, the Audic and Claverie method [106] was applied to all GO terms identified in all plant clusters. To make the number of GO terms associated with each cluster more manageable, GO slim analysis was performed with The Arabidopsis Information Resource (TAIR) GO slim for plants, while the Generic GO slim was applied to fungal unigenes.

\section{Analysis of gene expression with qPCR}

cDNA from S. lycopersicum and S. lycopersicoides obtained immediately after (0 hours after inoculation), 24 hours after, or 48 hours after inoculation with $B$. cinerea was used as template for qPCR. qPCR was performed by combining SYBR green master mix (Life Technologies, Grand Island, NY) with primers (Additional file 4) and template according to the manufacturers instructions and monitoring fluorescence during template amplification in a stratagene $\mathrm{M} \times 300 \mathrm{P}$ real-time $\mathrm{PCR}$ system (Agilent Technologies, Inc., Santa Clara, CA). The mean gene expression of three technical replications was normalized to expression of beta tubulin and calculated, relative to expression at 0 hours after inoculation, with the $2^{-\Delta \Delta C T}$ method [109].

\section{Metabolic pathway analysis}

Plant unigenes in each cluster were analyzed with the KEGG Automatic Annotation Server (KAAS) [110] to detect KEGG Orthologs (KO). KOs from clusters 1, 2, and 3 were combined into a single cluster representing up-regulated genes, while cluster 4 was kept separate to represent down-regulated genes. The KEGG Mapper Reconstruct Pathway tool was then used to highlight genes within KEGG pathways that were up- or downregulated in response to B.cinerea.

\section{Availability of supporting data}

The 454 reads for $S$. lycopersicoides inoculated with $B$. cinerea have been submitted to NCBI sequence read archive (SRA, http://www.ncbi.nlm.nih.gov/sra) under the accession number SRR1054293.

\section{Additional files}

\begin{abstract}
Additional file 1: Excel file of expression and predicted identity of S. lycopersicoides unigenes.

Additional file 2: KEGG analysis of the terpenoid backbone biosynthesis pathway in Solanum lycopersicoides. The KEGG

Automatic Annotation Service was used to assign KEGG Orthology (KO) identifiers to differentially expressed unigenes. The KO identifiers were then used to map unigenes to metabolic pathways. Genes highlighted in red indicate up-regulation in response to fungal infection. Genes highlighted in green indicate down-regulation in response to fungal infection. The pattern of gene expression indicates an activation of the mevalonate pathway in response to infection by $B$. cinerea.
\end{abstract}

Additional file 3: Excel file of expression and predicted identity of B. cinerea unigenes.

Additional file 4: Excel file of primers used for analysis of gene expression by qPCR.

Competing interests

The authors declare that they have no competing interests.

\section{Authors' contributions}

JES designed and performed experiments, analyzed data, and wrote the manuscript. BM and $\mathrm{HT}$ performed experiments. TM and BHB conceptualized experiments, supervised the research, analyzed data, and wrote the manuscript. All authors read and approved the final manuscript.

\section{Acknowledgments}

The authors would like to thank Jason Tipton for assistance with data analysis, and John Ridenour and Sandeep M.T. Sharma for careful review of the manuscript. This work was supported by the University of Arkansas Division of Agriculture funding to $\mathrm{BHB}$ and by Binational Agricultural Development Fund (BARD) funding to TM.

\section{Author details}

'Department of Plant Pathology, University of Arkansas Division of Agriculture, 217 Plant Sciences, Fayetteville, AR 72701, USA. ²Department of Botany and Plant Pathology, Purdue University, West Lafayette, IN, USA.

Received: 23 August 2013 Accepted: 25 April 2014 Published: 3 May 2014

\section{References}

1. Divon $\mathrm{HH}$, Fluhr R: Nutrition acquisition strategies during fungal infection of plants. FEMS Microbiol Lett 2007, 266(1):65-74.

2. Mendgen $\mathrm{K}$, Hahn M: Plant infection and the establishment of fungal biotrophy. Trends Plant Sci 2002, 7(8):352-356.

3. Perfect SE, Green JR: Infection structures of biotrophic and hemibiotrophic fungal plant pathogens. Mol Plant Pathol 2001, 2(2):101-108.

4. van Kan JAL: Licensed to kill: the lifestyle of a necrotrophic plant pathogen. Trends Plant Sci 2006, 11(5):247-253. 
5. Greenberg JT: Programmed cell death in plant-pathogen interactions. Annu Rev Plant Physiol Plant Mol Biol 1997, 48:525-545.

6. Govrin EM, Levine A: The hypersensitive response facilitates plant infection by the necrotrophic pathogen Botrytis cinerea. Curr Biol 2000, 10(13):751-757.

7. Glazebrook J: Contrasting mechanisms of defense against biotrophic and necrotrophic pathogens. Annu Rev Phytopathol 2005, 43:205-227.

8. Mengiste T: Plant Immunity to Necrotrophs. Annu Rev Phytopathol 2012, 50:267-294.

9. Schulze-Lefert P, Panstruga R: Establishment of biotrophy by parasitic fungi and reprogramming of host cells for disease resistance. Annu Rev Phytopathol 2003, 41:641-667.

10. Dodds PN, Rafiqi M, Gan PHP, Hardham AR, Jones DA, Ellis JG: Effectors of biotrophic fungi and oomycetes: pathogenicity factors and triggers of host resistance. New Phytol 2009, 183(4):993-999.

11. Laluk K, Mengiste T: Necrotroph attacks on plants: wanton destruction or covert extortion? Arabidopsis Book 2010, 8:e0136.

12. Friesen TL, Faris JD, Solomon PS, Oliver RP: Host-specific toxins: effectors of necrotrophic pathogenicity. Cell Microbiol 2008, 10(7):1421-1428.

13. Jarvis WR: Botryotinia and Botrytis species: taxonomy, physiology, and pathogenicity. In Monograph, Research Branch Canada Department of Agriculture; 1977

14. Genescope. http://www.cns.fr/spip/Botrytis-cinerea-estimated-losses.html.

15. Colmenares AJ, Aleu J, Duran-Patron R, Collado IG, Hernandez-Galan R: The putative role of botrydial and related metabolites in the infection mechanism of Botrytis cinerea. J Chem Ecol 2002, 28(5):997-1005.

16. Cutler HG, Parker SR, Ross SA, Crumley FG, Schreiner PR: Homobotcinolide: a biologically active natural homolog of botcinolide from Botrytis cinerea. Biosci Biotechnol Biochem 1996, 60(4):656-658

17. Choquer M, Fournier E, Kunz C, Levis C, Pradier J-M, Simon A, Viaud M: Botrytis cinerea virulence factors: new insights into a necrotrophic and polyphageous pathogen. FEMS Microbiol Lett 2007, 277(1):1-10.

18. Williamson B, Tudzynski B, Tudzynski P, Van Kan JAL: Botrytis cinerea: the cause of grey mould disease. Mol Plant Pathol 2007, 8(5):561-580.

19. Tani H, Koshino H, Sakuno E, Nakajima H: Botcinins A, B, C, and D, metabolites produced by Botrytis cinerea, and their antifungal activity against Magnaporthe grisea, a pathogen of rice blast disease. J Nat Prod 2005, 68(12):1768-1772.

20. Tani H, Koshino H, Sakuno E, Cutler HG, Nakajima H: Botcinins E and F and botcinolide from Botrytis cinerea and structural revision of botcinolides. J Nat Prod 2006, 69(4):722-725.

21. Dalmais B, Schumacher J, Moraga J, Le Pecheur P, Tudzynski B, Gonzalez Collado I, Viaud M: The Botrytis cinerea phytotoxin botcinic acid requires two polyketide synthases for production and has a redundant role in virulence with botrydial. Mol Plant Pathol 2011, 12(6):564-579.

22. Shahbazi $H$, Aminian $H$, Sahebani $N$, Halterman D: Effect of Alternaria solani exudates on resistant and susceptible potato cultivars from two different pathogen isolates. Plant Pathol J 2011, 27(1):14-19.

23. Pound GS, Stahmann MA: The production of a toxic material by Alternaria solani and its relation to the early blight disease of tomato. Phytopathology 1951, 41:1104-1114

24. Langsdorf G, Furuichi N, Doke N, Nishimura S: Investigations on Alternaria solani infections: detection of alternaric acid and a susceptibility-inducing factor in the spore-germination fluid of A. solani. J Phytopathol 1990, 128(4):271-282.

25. Ichihara A, Sakamura S, Tazaki H: Solanapyrones A, B and C, phytotoxic metabolites from the fungus Alternaria solani. Tetrahedron Lett 1983, 24(48):5373-5376.

26. Rigano MM, De Guzman G, Walmsley AM, Frusciante L, Barone A: Production of pharmaceutical proteins in solanaceae food crops. Int $J$ Mol Sci 2013, 14(2):2753-2773.

27. ten Have A, van Berloo R, Lindhout $P$, van Kan JAL: Partial stem and leaf resistance against the fungal pathogen Botrytis cinerea in wild relatives of tomato. Eur J Plant Pathol 2007, 117(2):153-166.

28. Chaerani R, Groenwold R, Stam P, Voorrips RE: Assessment of early blight (Alternaria solani) resistance in tomato using a droplet inoculation method. J Gen Plant Pathol 2007, 73(2):96-103.

29. Gianessi L, Reigner N: The importance of fungicides in U.S. crop production. Outlooks on Pest Management 2006, 17(5):209-213.

30. Guimaraes RL, Chetelat RT, Stotz HU: Resistance to Botrytis cinerea in Solanum lycopersicoides is dominant in hybrids with tomato, and involves induced hyphal death. Eur J Plant Pathol 2004, 110(1):13-23.
31. Chetelat RT, Cisneros P, Stamova L, Rick CM: A male-fertile Lycopersicon esculentum $x$ Solanum lycopersicoides hybrid enables direct backcrossing to tomato at the diploid level. Euphytica 1997, 95(1):99-108

32. Finkers $R$, Bai $Y$, Berg $P$, Berloo R, Meijer-Dekens F, Have A, Kan J, Lindhout $P$, Heusden A: Quantitative resistance to Botrytis cinerea from Solanum neorickii. Euphytica 2008, 159(1/2):83-92.

33. Egashira H, Kuwashima A, Ishiguro H, Fukushima K, Kaya T, Imanishi S: Screening of wild accessions resistant to grey mold (Botrytis cinerea Pers.) in Lycopersicon. Acta Physiol Plant 2000, 22(3):324-326.

34. Canady MA, Meglic V, Chetelat RT: A library of Solanum lycopersicoides introgression lines in cultivated tomato. Genome 2005, 48(4):685-697.

35. Eshed Y, Zamir D: An introgression line population of Lycopersicon pennellii in the cultivated tomato enables the identification and fine mapping of yield-associated QTL. Genetics 1995, 141(3):1147-1162.

36. Blanca J, Cañzares J, Cordero L, Pascual L, Diez MJ, Nuez F: Variation revealed by SNP genotyping and morphology provides insight into the origin of the tomato. PLOS One 2012, 7(10):1-17.

37. Amselem J, Cuomo CA, van Kan JAL, Viaud M, Benito EP, Couloux A, Coutinho PM, de Vries RP, Dyer PS, Fillinger S, Fournier E, Gout L, Hahn M, Kohn L, Lapalu N, Plummer KM, Pradier J-M, Quévillon E, Sharon A, Simon A, ten Have A, Tudzynski B, Tudzynski P, Wincker P, Andrew M, Anthouard V, Beever RE, Beffa R, Benoit I, Bouzid O: Genomic analysis of the necrotrophic fungal pathogens Sclerotinia sclerotiorum and Botrytis cinerea. PLOS Genet 2011, 7(8):e1002230-e1002230.

38. Sato S, Tabata S, Hirakawa H, Asamizu E, Shirasawa K, Isobe S, Kaneko T, Nakamura Y, Shibata D, Aoki K, Egholm M, Knight J, Bogden R, Li C, Shuang Y, Xu X, Pan S, Cheng S, Liu X, Ren Y, Wang J, Albiero A, Dal Pero F, Todesco S, Van Eck J, Buels RM, Bombarely A, Gosselin JR, Huang M, Leto JA: The tomato genome sequence provides insights into fleshy fruit evolution. Nature 2012, 485(7400):635-641.

39. Camon E, Magrane M, Barrell D, Lee V, Dimmer E, Maslen J, Binns D, Harte N, Lopez R, Apweiler R: The Gene Ontology Annotation (GOA) database: sharing knowledge in uniprot with gene ontology. Nucleic Acids Res 2004, 32(Database issue):D262-D266.

40. Windram O, Madhou P, McHattie S, Hill C, Hickman R, Cooke E, Jenkins DJ, Penfold CA, Baxter L, Breeze E, Kiddle SJ, Rhodes J, Atwell S, Kliebenstein DJ, Kim Y-S, Stegle O, Borgwardt K, Zhang C, Tabrett A, Legaie R, Moore J, Finkenstadt B, Wild DL, Mead A, Rand D, Beynon J, Ott S, Buchanan-Wollaston V, Denby KJ: Arabidopsis defense against Botrytis cinerea: chronology and regulation deciphered by high-resolution temporal transcriptomic analysis. Plant Cell 2012, 24(9):3530-3557.

41. De Cremer K, Mathys J, Vos C, Froenicke L, Michelmore RW, Cammue BPA, De Coninck B: RNAseq-based transcriptome analysis of Lactuca sativa infected by the fungal necrotroph Botrytis cinerea. Plant Cell Environ 2013, 36(11):1992-2007.

42. Berger S, Papadopoulos M, Schreiber U, Kaiser W, Roitsch T: Complex regulation of gene expression, photosynthesis and sugar levels by pathogen infection in tomato. Physiol Plant 2004, 122(4):419-428.

43. Sánchez-Vallet A, López G, Ramos B, Delgado-Cerezo M, Riviere M-P, Llorente F, Fernández PV, Miedes E, Estevez JM, Grant M, Molina A: Disruption of abscisic acid signaling constitutively activates Arabidopsis resistance to the necrotrophic fungus Plectosphaerella cucumerina. Plant Physiol 2012 160(4):2109-2124.

44. Loon LC, Rep M, Pieterse CMJ: Significance of inducible defense-related proteins in infected plants. Annu Rev Phytopathol 2006, 44:135-162.

45. Kamoun S: A catalogue of the effector secretome of plant pathogenic oomycetes. Annu Rev Phytopathol 2006, 44:41-60.

46. AbuQamar S, Chen X, Dhawan R, Bluhm B, Salmeron J, Lam S, Dietrich RA Mengiste $\mathrm{T}$ : Expression profiling and mutant analysis reveals complex regulatory networks involved in Arabidopsis response to Botrytis infection. Plant J 2006, 48(1):28-44.

47. Marrs KA: The functions and regulation of glutathione S-transferases in plants. Annu Rev Plant Physiol Plant Mol Biol 1996, 47:127-158.

48. Bianchini GM, Paiva NL, Stermer BA: Induction of early mevalonate pathway enzymes and biosynthesis of end products in potato (Solanum tuberosum) tubers by wounding and elicitation. Phytochemistry 1996, 42(6):1563-1571.

49. Ha SH, Kim JB, Hwang YS, Lee SW: Molecular characterization of three 3-hydroxy-3-methylglutaryl-CoA reductase genes including pathogen-induced Hmg2 from pepper (Capsicum annuum). Biochim Biophys Acta 2003, 1625(3):253-260. 
50. Dubey VS, Bhalla R, Luthra R: An overview of the non-mevalonate pathway for terpenoid biosynthesis in plants. J Biosci 2003, 28(5):637-646.

51. Xiao Y, Savchenko T, Baidoo EEK, Chehab WE, Hayden DM, Tolstikov V, Corwin JA, Kliebenstein DJ, Keasling JD, Dehesh K: Retrograde signaling by the plastidial metabolite MEcPP regulates expression of nuclear stress-response genes. Cell 2012, 149(7):1525-1535.

52. Gil MJ, Coego A, Mauch-Mani B, Jordá L, Vera P: The Arabidopsis csb3 mutant reveals a regulatory link between salicylic acid-mediated disease resistance and the methyl-erythritol 4-phosphate pathway. Plant J 2005, 44(1):155-166.

53. Guest D, Brown J: Plant defences against pathogens. In Plant pathogens and plant diseases. Edited by Brown J, Ogle H. Armidale: Rockvale Publications; 1997:263-286.

54. ten Have A, Mulder W, Visser J, van Kan JA: The endopolygalacturonase gene Bcpg1 is required for full virulence of Botrytis cinerea. Mol Plant Microbe Interact 1998, 11(10):1009-1016.

55. Rolke $Y$, Liu S, Quidde T, Williamson B, Schouten A, Weltring K-M, Siewers V, Tenberge KB, Tudzynski B, Tudzynski P: Functional analysis of $\mathrm{H}(2) \mathrm{O}$ (2)-generating systems in Botrytis cinerea: the major $\mathrm{Cu}-\mathrm{Zn}$-superoxide dismutase (BCSOD1) contributes to virulence on French bean, whereas a glucose oxidase (BCGOD1) is dispensable. Mol Plant Pathol 2004 5(1):17-27.

56. Pinedo C, Wang C-M, Pradier J-M, Dalmais B, Choquer M, Le Pêcheur $P$, Morgant G, Collado IG, Cane DE, Viaud M: Sesquiterpene synthase from the botrydial biosynthetic gene cluster of the phytopathogen Botrytis cinerea. ACS Chem Biol 2008, 3(12):791-801.

57. Wang C-M, Hopson R, Lin X, Cane DE: Biosynthesis of the sesquiterpene botrydial in Botrytis cinerea. Mechanism and stereochemistry of the enzymatic formation of presilphiperfolan-8beta-ol. J Am Chem Soc 2009, 131(24):8360-8361.

58. Zhao L, Qiu C, Li J, Chai Y, Kai G, Li Z, Sun X, Tang KX: Investigation of disease resistance and cold tolerance of Solanum lycopersicoides for tomato improvement. HortSci 2005, 40(1):43-46.

59. Jones JDG, Dangl JL: The plant immune system. Nature 2006 444(7117):323-329

60. Lorang JM, Sweat TA, Wolpert TJ: Plant disease susceptibility conferred by a "resistance" gene. Proc Natl Acad Sci U S A 2007, 104(37):14861-14866.

61. Faris JD, Zhang Z, Lu H, Lu S, Reddy L, Cloutier S, Fellers JP, Meinhardt SW Rasmussen JB, Xu SS, Oliver RP, Simons KJ, Friesen TL: A unique wheat disease resistance-like gene governs effector-triggered susceptibility to necrotrophic pathogens. Proc Natl Acad Sci U S A 2010, 107(30):13544-13549.

62. Nagy ED, Lee T-C, Ramakrishna W, Xu Z, Klein PE, SanMiguel P, Cheng C-P, Li J, Devos KM, Schertz K, Dunkle L, Bennetzen JL: Fine mapping of the PC locus of Sorghum bicolor, a gene controlling the reaction to a fungal pathogen and its host-selective toxin. Theor App/ Genet 2007, 114(6):961-970.

63. Edlich W, Lorenz G, Lyr H, Nega E, Pommer EH: New aspects on the infection mechanism of Botrytis cinerea Pers. Neth J Plant Pathol 1989, 95:53-62.

64. Spoel SH, Johnson JS, Dong X: Regulation of tradeoffs between plant defenses against pathogens with different lifestyles. Proc Natl Acad Sci U S A 2007, 104(47):18842-18847.

65. Veronese P, Nakagami H, Bluhm B, AbuQamar S, Chen X, Salmeron J, Dietrich RA, Hirt H, Mengiste T: The membrane-anchored BOTRYTIS-INDUCED KINASE1 plays distinct roles in Arabidopsis resistance to necrotrophic and biotrophic pathogens. Plant Cell 2006, 18(1):257-273.

66. Delaney TP, Uknes S: A central role of salicylic acid in plant disease resistance. Science 1994, 266(5188):1247.

67. Thomma BP, Eggermont K, Penninckx IA, Mauch-Mani B, Vogelsang R, Cammue BP, Broekaert WF: Separate jasmonate-dependent and salicylate-dependent defense-response pathways in Arabidopsis are essential for resistance to distinct microbial pathogens. Proc Natl Acad Sci U S A 1998, 95(25):15107-15111.

68. Cao H, Glazebrook J, Clarke JD, Volko S, Dong X: The Arabidopsis NPR1 gene that controls systemic acquired resistance encodes a novel protein containing ankyrin repeats. Cell 1997, 88(1):57-63.

69. Reuber TL, Plotnikova JM, Dewdney J, Rogers EE, Wood W, Ausubel FM: Correlation of defense gene induction defects with powdery mildew susceptibility in Arabidopsis enhanced disease susceptibility mutants. Plant J 1998, 16(4):473-485.
70. Dempsey DA, Klessig DF, Shah J: Salicylic acid and disease resistance in plants. Crit Rev Plant Sci 1999, 18(4):547-575

71. Kachroo P, Shanklin J, Shah J, Whittle EJ, Klessig DF: A fatty acid desaturase modulates the activation of defense signaling pathways in plants. Proc Natl Acad Sci U S A 2001, 98(16):9448-9453.

72. Govrin EM, Levine A: Infection of Arabidopsis with a necrotrophic pathogen, Botrytis cinerea, elicits various defense responses but does not induce systemic acquired resistance (SAR). Plant Mol Biol 2002, 48(3):267-276.

73. Thomma BP, Eggermont K, Tierens KF, Broekaert WF: Requirement of functional ethylene-insensitive 2 gene for efficient resistance of Arabidopsis to infection by Botrytis cinerea. Plant Physiol 1999, 121(4):1093-1102.

74. Métraux JP, Signer H, Ryals J, Ward E, Wyss-Benz M, Gaudin J, Raschdorf K, Schmid E, Blum W, Inverardi B: Increase in salicylic Acid at the onset of systemic acquired resistance in cucumber. Science 1990, 250(4983):1004-1006.

75. Gaffney T, Friedrich L, Vernooij B, Negrotto D, Nye G, Uknes S, Ward E, Kessmann H, Ryals J: Requirement of salicylic Acid for the induction of systemic acquired resistance. Science 1993, 261(5122):754-756.

76. Kunkel BN, Brooks DM: Cross talk between signaling pathways in pathogen defense. Curr Opin Plant Biol 2002, 5(4):325-331.

77. Anderson JP, Badruzsaufari E, Schenk PM, Manners JM, Desmond OJ, Ehlert C, Maclean DJ, Ebert PR, Kazan K: Antagonistic interaction between abscisic acid and jasmonate-ethylene signaling pathways modulates defense gene expression and disease resistance in Arabidopsis. Plant Cell 2004, 16(12):3460-3479.

78. Mang HG, Laluk KA, Parsons EP, Kosma DK, Cooper BR, Park HC, AbuQamar S, Boccongelli C, Miyazaki S, Consiglio F, Chilosi G, Bohnert HJ, Bressan RA, Mengiste T, Jenks MA: The Arabidopsis RESURRECTION1 gene regulates a novel antagonistic interaction in plant defense to biotrophs and necrotrophs. Plant Physiol 2009, 151(1):290-305.

79. Abuqamar S, Chai M-F, Luo H, Song F, Mengiste T: Tomato protein kinase $1 \mathrm{~b}$ mediates signaling of plant responses to necrotrophic fungi and insect herbivory. Plant Cell 2008, 20(7):1964-1983.

80. Abuqamar S, Luo H, Laluk K, Mickelbart MV, Mengiste T: Crosstalk between biotic and abiotic stress responses in tomato is mediated by the AIM1 transcription factor. Plant J 2009, 58(2):347-360.

81. Zheng Z, Qamar SA, Chen Z, Mengiste T: Arabidopsis WRKY33 transcription factor is required for resistance to necrotrophic fungal pathogens. Plant J 2006, 48(4):592-605.

82. Mengiste T, Chen X, Salmeron J, Dietrich R: The BOTRYTIS SUSCEPTIBLE1 gene encodes an R2R3MYB transcription factor protein that is required for biotic and abiotic stress responses in Arabidopsis. Plant Cell 2003, 15(11):2551-2565.

83. Lorenzo O, Chico JM, Sánchez-Serrano JJ, Solano R: JASMONATE-INSENSITIVE1 encodes a MYC transcription factor essential to discriminate between different jasmonate-regulated defense responses in Arabidopsis. Plant Cell 2004, 16(7):1938-1950.

84. Bethke G, Unthan T, Uhrig JF, Pöschl Y, Gust AA, Scheel D, Lee J: Flg22 regulates the release of an ethylene response factor substrate from MAP kinase 6 in Arabidopsis thaliana via ethylene signaling. Proc Natl Acad Sci U S A 2009, 106(19):8067-8072.

85. Nurmberg PL, Knox KA, Yun B-W, Morris PC, Shafiei R, Hudson A, Loake GJ: The developmental selector AS1 is an evolutionarily conserved regulator of the plant immune response. Proc Natl Acad Sci U S A 2007. 104(47):18795-18800

86. Coego A, Ramirez V, Gil MJ, Flors V, Mauch-Mani B, Vera P: An Arabidopsis homeodomain transcription factor, OVEREXPRESSOR OF CATIONIC PEROXIDASE 3, mediates resistance to infection by necrotrophic pathogens. Plant Cell 2005, 17(7):2123-2137.

87. Kidd BN, Edgar Cl, Kumar KK, Aitken EA, Schenk PM, Manners JM, Kazan K: The mediator complex subunit PFT1 is a key regulator of jasmonatedependent defense in Arabidopsis. Plant Cell 2009, 21(8):2237-2252.

88. Dhawan R, Luo H, Foerster AM, Abuqamar S, Du H-N, Briggs SD, Mittelsten Scheid O, Mengiste T: HISTONE MONOUBIQUITINATION1 interacts with a subunit of the mediator complex and regulates defense against necrotrophic fungal pathogens in Arabidopsis. Plant Cell 2009, 21(3):1000-1019.

89. Walley JW, Rowe HC, Xiao Y, Chehab EW, Kliebenstein DJ, Wagner D, Dehesh K: The chromatin remodeler SPLAYED regulates specific stress signaling pathways. PLoS Pathog 2008, 4(12):e1000237-e1000237.

90. Zhou C, Zhang L, Duan J, Miki B, Wu K: HISTONE DEACETYLASE19 is involved in jasmonic acid and ethylene signaling of pathogen response in Arabidopsis. Plant Cell 2005, 17(4):1196-1204. 
91. Berr A, McCallum EJ, Alioua A, Heintz D, Heitz T, Shen W-H: Arabidopsis histone methyltransferase SET DOMAIN GROUP8 mediates induction of the jasmonate/ethylene pathway genes in plant defense response to necrotrophic fungi. Plant Physiol 2010, 154(3):1403-1414.

92. Cantu D, Vicente AR, Greve LC, Dewey FM, Bennett AB, Labavitch JM, Powell ALT: The intersection between cell wall disassembly, ripening, and fruit susceptibility to Botrytis cinerea. Proc Natl Acad Sci U S A 2008, 105(3):859-864.

93. Bessire $M$, Chassot C, Jacquat A-C, Humphry M, Borel S, Petétot JM-C, Métraux J-P, Nawrath C: A permeable cuticle in Arabidopsis leads to a strong resistance to Botrytis cinerea. EMBO J 2007, 26(8):2158-2168.

94. Chassot C, Nawrath C, Métraux J-P: Cuticular defects lead to full immunity to a major plant pathogen. Plant J 2007, 49(6):972-980.

95. Tang D, Simonich MT, Innes RW: Mutations in LACS2, a long-chain acyl-coenzyme A synthetase, enhance susceptibility to avirulent Pseudomonas syringae but confer resistance to Botrytis cinerea in Arabidopsis. Plant Physiol 2007, 144(2):1093-1103.

96. Hernández-Blanco C, Feng DX, Hu J, Sánchez-Vallet A, Deslandes L, Llorente F, Berrocal-Lobo M, Keller H, Barlet X, Sánchez-Rodríguez C, Anderson LK, Somerville S, Marco Y, Molina A: Impairment of cellulose synthases required for Arabidopsis secondary cell wall formation enhances disease resistance. Plant Cell 2007, 19(3):890-903.

97. Rohmer M: The mevalonate-independent methylerythritol 4-phosphate (MEP) pathway for isoprenoid biosynthesis, including carotenoids. Pure Appl Chem 1999, 71(12):2279-2284.

98. Stermer BA, Bianchini GM, Korth KL: Regulation of HMG-CoA reductase activity in plants. J Lipid Res 1994, 35(7):1133-1140.

99. Santos CS, Pinheiro M, Silva Al, Egas C, Vasconcelos MW: Searching for resistance genes to Bursaphelenchus xylophilus using high throughput screening. BMC Genomics 2012, 13:599-599.

100. Huth TJ, Place SP: De novo assembly and characterization of tissue specific transcriptomes in the emerald notothen, Trematomus bernacchii. BMC Genomics 2013, 14:805-805.

101. Olsvik PA, Vikeså V, Lie KK, Hevrøy EM: Transcriptional responses to temperature and low oxygen stress in Atlantic salmon studied with next-generation sequencing technology. BMC Genomics 2013, 14:817-817.

102. Ries L, Pullan ST, Delmas S, Malla S, Blythe MJ, Archer DB: Genome-wide transcriptional response of Trichoderma reesei to lignocellulose using RNA sequencing and comparison with Aspergillus niger. BMC Genomics 2013, 14(1):1-12.

103. Tremblay A, Hosseini P, Li S, Alkharouf NW, Matthews BF: Analysis of Phakopsora pachyrhizi transcript abundance in critical pathways at four time-points during infection of a susceptible soybean cultivar using deep sequencing. BMC Genomics 2013, 14:614-614.

104. de Sio F, Laratta B, Giovane A, Quagliuolo L, Castaldo D, Servillo L: Analysis of free and esterified ergosterol in tomato products. J Agric Food Chem 2000, 48(3):780-784.

105. Conesa A, Götz S, García-Gómez JM, Terol J, Talón M, Robles M: Blast2GO: a universal tool for annotation, visualization and analysis in functional genomics research. Bioinformatics 2005, 21(18):3674-3676.

106. Audic S, Claverie JM: The significance of digital gene expression profiles. Genome Res 1997, 7(10):986-995.

107. Sturn A, Quackenbush J, Trajanoski Z: Genesis: cluster analysis of microarray data. Bioinformatics 2002, 18(1):207-208.

108. Zdobnov EM, Apweiler R: InterProScan-an integration platform for the signature-recognition methods in InterPro. Bioinformatics 2001, 17(9):847-848.

109. Livak KJ, Schmittgen TD: Analysis of relative gene expression data using real-time quantitative PCR and the 2(-Delta Delta C (T)) Method. Methods 2001, 25(4):402-408.

110. Moriya Y, Itoh M, Okuda S, Yoshizawa AC, Kanehisa M: KAAS: an automatic genome annotation and pathway reconstruction server. Nucleic Acids Res 2007, 35(Web Server issue):W182-W185.

doi:10.1186/1471-2164-15-334

Cite this article as: Smith et al:: Resistance to Botrytis cinerea in

Solanum lycopersicoides involves widespread transcriptional reprogramming. BMC Genomics 2014 15:334.

\section{Submit your next manuscript to BioMed Central and take full advantage of:}

- Convenient online submission

- Thorough peer review

- No space constraints or color figure charges

- Immediate publication on acceptance

- Inclusion in PubMed, CAS, Scopus and Google Scholar

- Research which is freely available for redistribution

Submit your manuscript at www.biomedcentral.com/submit
() Biomed Central 